\title{
NBS Research
}

REFERENCE

\section{Reports}

NIST

PUBLICATIONS 
Cover photo: In a demon. stration of the Meissner effect, a permanent magnet floats above a Y-Ba-Cu-O superconductor at $77 \mathrm{~K}$. Potential applications of the magnetic repulsion of superconductors include levitating trains, frictionfree bearings, and magnetic shielding. See page 5 for article describing NBS superconductivity research. 


\section{CONTENTS}

Research Update 2

Riding a Heat Wave:

Researchers Take Another Look at Superconductivity

President Reagan Announces Superconductivity Initiative

14

Life on the Edge: Measuring Linewidths

Thin-Film Thermocouples Designed for Diesel Engine Research

Concrete Research at NBS:

New Ways to Understand an Old Material

Improved Clinical Lab Tests: Goal of Cooperative Program

Emerging Technologies:

The Competitive Edge of the Future?

High-Technology Bugs Are New Tools

for Science and Industry

New Publications

Conference Calendar

U.S. DEPARTMENT OF COMMERCE

Clarence J. Brown, Acting Secretary

National Bureau of Standards

Ernest Ambler, Director

National Bureau of Standards

Galthersburg. MD 20899

301/975-2000

Natıonal Bureau of Standards

Boulder, CO 80303

$303 / 497-3000$

August 1987

NBS Special Publication 733

Prepared by the Public Information Division

A903 Administration Building

Natıonal Bureau of Standards

Gathersburg, MD 20899

301/975-2762

Library of Congress

Catalog Card Number

87.619861

CODEN:XNBSAV

Any mention of commercial products

Is for information only; it does not

imply recommendation or endorsement

by the National Bureau of Standards

nor does it imply that the products

mentioned are necessarily the best

available for the purpose. 
ECOND SPACE-MADE PRODUCT IS NEW MEASUREMENT TOOL

The second commercial spacemade product, Standard

Reference Material (SRM) 1961

30-Micrometer Polystyrene Spheres, is a new small-particle measurement standard developed for industry by NBS. It is an important quality control tool for chemists using powders for the manufacture of pharmaceuticals, chemicals, industrial compounds, and products that require particle sizing near 30 micrometers. Like SRM 1960, 10-Micrometer Polystyrene Spheres-the first commercial space-made product offered by NBS in 1985, the new SRM 1961 was made in space by the National Aeronautics and Space Administration because a low-gravity environment produces a product that is more uniform in size and shape than Earth-bound processes for polystyrene materials of this size SRM 1961 is a 5-milliliter vial with approximately 1 million of the 30-micrometer spheres suspended in water. It is available for \$608 from the Office of Standard Reference Materials, B311 Chemistry Building, NBS, Gaithersburg, MD 20899, 301/975-OSRM (6776).

\section{UREAU SUCCESSFULLY OPERATES 1O-VOLT JOSEPHSON ARRAY}

Researchers at the NBS Boulder laboratories have achieved an extremely precise 10-volt output from an array of 14,184 superconducting Josephson junctions. The array may eventually serve as a new standard for the U.S. legal volt at an unprecedented level of accuracy for this voltage. Development of the array was driven by increasing demands for calibration of popular 10-volt Zener diode standards. Such standards are gradually replacing 1 -volt Weston-type cells as secondary standards in industrial and military laboratories around the country. Each

Josephson junction can generate only a few millivolts. Previous 1- or 2-junction Josephson standards required a complicated resistance bridge in compare the tiny standard voltage with that of devices being calibrated
Increased accuracy is possible, however, when many Josephson junctions in series can be fabricated on a single chip, eliminating the need for the resistance bridge. The array of 14,184 Josephson junctions operated by NBS researchers realizes a voltage standard at a more useful level-10 volts. These long arrays of superconducting junctions are constructed using technology borrowed from the semiconductor integrated circuit industry, substituting thin films of superconducting metals such as lead and niobium for the semiconductors.

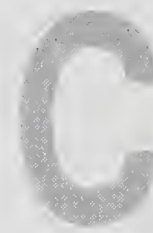

\section{OMPUTER VISION SYSTEMS} STUDIED

NBS and Martin Marietta Baltimore Aerospace have begun a joint research program to develop a series of advanced computer-vision algorithms using the parallel image processing engine (PIPE), a specialized imageprocessing computer invented at NBS. Researchers from both organizations will work on algorithms for stereo analysis, sparse depth maps, two-dimensional feature extraction-including color and texture as well as geometric features, image flow, and three-dimensional range information. The algorithms will be applicable to a wide variety of computer vision problems.

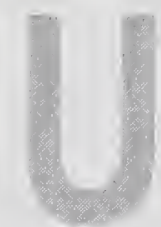

SERS, VENDORS COMPLETE OSINET FILE TRANSFER TESTS

A group of 13 computer users and vendors was the first to complete a series of tests across OSINET, an experimental computer network for Open Systems Interconnection (OSI) standards. Group members succeeded in accessing, transferring, and managing files as well as demonstrating that their OSI systems could work together Coordinated by NBS, this network is helping to speed the development and use of commercial OSI products in industry and government.

Twenty-two computer and communications manufacturers and users, including several government agencies, are participatıng in the program. OSINET participants have developed their implementations of OSI standards, called protocols. Using these implementations to communicate with each other and with the network information center located in the NBS Institute for Computer Sciences and Technology, product developers are able to verify that their systems work with other systems. The file transfer protocol implementations used by the OSINET participants are based on agreements reached at the ongoing NBS workshops for implementors of OSI.

More than 200 computer manufacturers, semiconductor manufacturers, word processing vendors, process control vendors, communication carriers, and industry and government users participate in the workshops to advance the development of commercial products implementing OSI standards. The OSINET steering committee has invited nonparticipants to submit proposals for joining the network. For more information, contact Gerard Mulvenna, B217 Technology Building, NBS,

Gaithersburg, MD 20899, 301/975-3631.

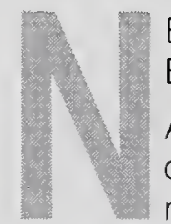
BS RECOMMENDS 400TH ENERGY-RELATED INVENTION A new process for continuous casting of steel cylinders used in manufacturing seamless pipe and tubing recently became the 400th invention to be recommended by NBS to the Department of Energy (DOE) for possible assistance in development and marketing. Through the Energy-Related Inventions Program, conducted jointly by NBS and DOE, inventors can receive help in getting their ideas from the workshop to the marketplace. NBS provides, at no cost to the inventor, evaluations of energyrelated inventions and recommends those it considers promising to DOE. In turn, DOE can provide financial support or help in marketing an inventor's idea. The one-time DOE grants typically have ranged between $\$ 50,000$ and $\$ 200,000$, with an average of $\$ 80,000$ per invention. Those with ideas that will help save energy or who would like more information on the program should write to the Office of Energy-Related Inventions, Rm. 209 Engineering Mechanics Building, NBS, Gaithersburg, MD 20899. 
MALL-ANGLE X-RAY

SCATTERING FACILITY

AVAILABLE FOR RESEARCH

A new small-angle $x$-ray scattering (SAXS) facility at the NBS

Gaithersburg, Maryland, laboratories is now available to scientists in industry, government, and universities for cooperative and proprietary research on the microstructures of polymers, metals, ceramics, and biological materials. The SAXS instrument uses a 12-kilowatt rotating anode generator to produce a highly collimated pinhole beam of

$x$ rays that can probe the internal structures of materials in the 1-to 100-nanometer size range. The $x$-ray scattering pattern is picked up on a two-dimensional detector recorded, and displayed on a color graphics system. For information on the NBS SAXS facility or to schedule cooperative or proprietary research time, contact Dr. John D. Barnes, B210 Polymer Building, NBS, Gaithersburg, MD 20899, 301/975-6786

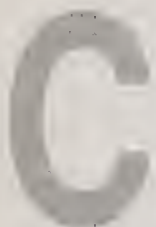

ONSORTIUM FORMED TO IMPROVE PROCESSING OF METAL POWDERS

NBS has organized a new consortium to develop the basic measurement system needed by industry for the automated or "intelligent" processing of rapidly solidified metal powders by high-pressure, inert gas atomization. The cooperative 3 -year program is open to researchers from industry, universities, and government agencies who are concerned about quality control in the production of rapidly solidified metal powders used to make aerospace and other high-technology products that require materials with superior performance.

Better control of the atomization of liquid metals is needed to produce powders with the desired microstructures for advanced materials. Current powder production is labor intensive and product yield can be improved.

ALCOA, Crucible Materials Corp. General Electric Co., and Hoaganaes Corp have already joined the consortium. For information on the consortium, or to jorn the program by providing either funds or researchers, contact Dr. H. Thomas Yolken, B344 Materials Building, NBS,

Gaithersburg, MD 20899, 301/975-5727.

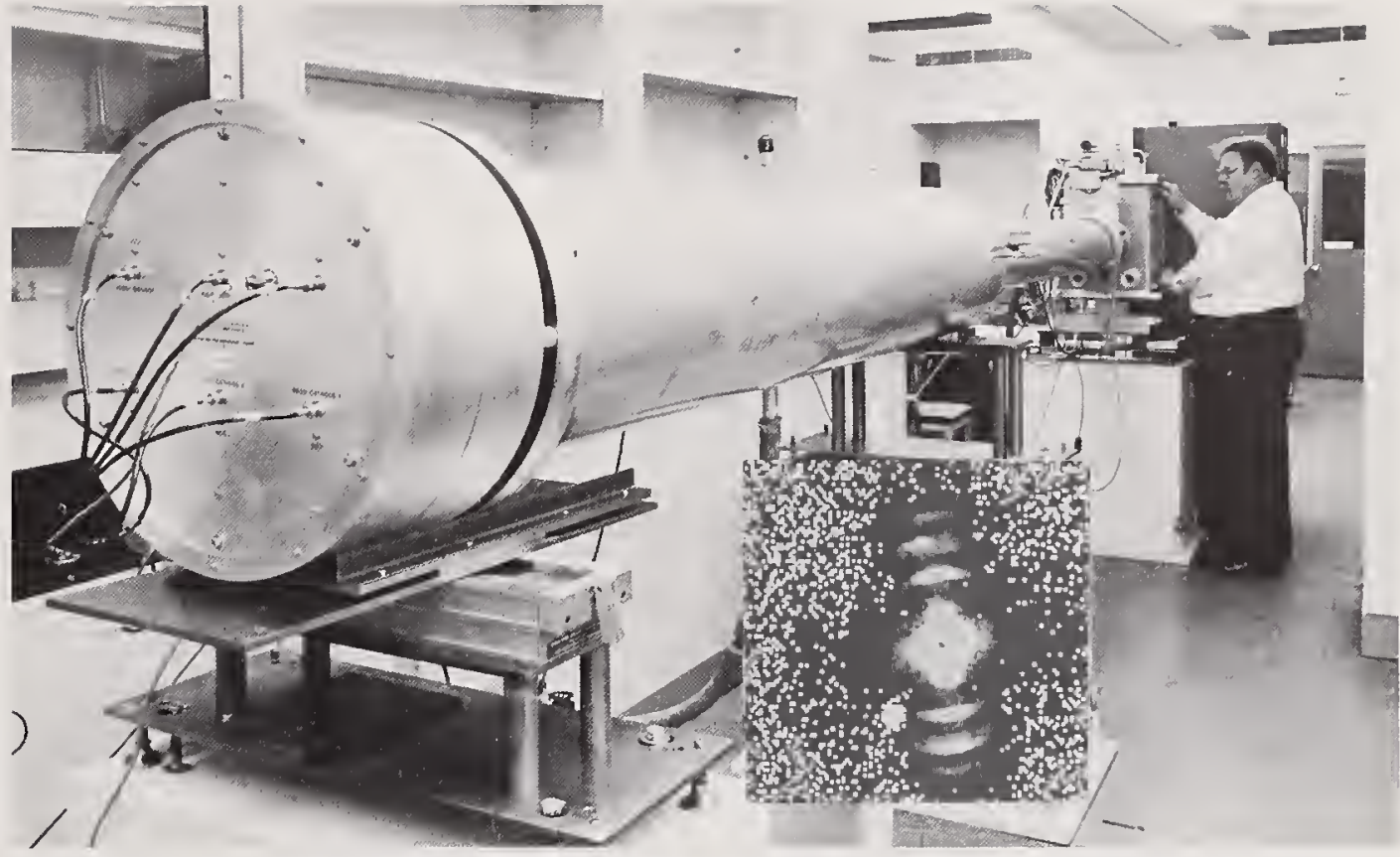

The small-angle x-ray scattering facility is used by NBS polymer physicist Dr. John Barnes to obtain information on the microstructures of polymer blends to develop polymer alloy phase diagrams. Inset shows $x$-ray scattering pattern.

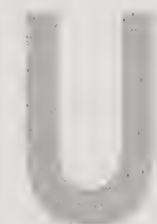

LTRA-CLEAN CERAMIC PROCESSING LAB SET UP

One of the barriers to the widespread use of advanced ceramics is the inability of manufacturers to produce materials with consistent performance. Impurities in ceramic powders during compaction, calcination, and sintering can affect the microstructures and other properties of advanced materials used in hightemperature engines and turbines, semiconductors, superconductors, and other aerospace and electronic products.

To study the effects of contamination on the processing and composition of advanced ceramics, NBS has established a clean room facility for producing powders and sample materials with controlled levels of impurities and dopants. The laboratory, which has special work areas where several different projects can be conducted simultaneously without cross contamination of materials, includes a laminar flow work area with class-10 clean room conditions and such laboratory equipment as a rotary evaporator, drying oven, a press for making pellets, and controlledatmosphere furnaces. For information on the facility, which is available for cooperative research, write or call Dr. John Blendell, A258 Materials Building, NBS, Gaithersburg, MD 20899, 301/975-5796

OINT AGREEMENT WILL EXAMINE IMPROVED CHEMICAL ANALYSIS

Dionex Corp., a major producer of ion chromatographic equip ment, has signed a cooperative agreement with NBS that aims to improve methods of separating transition elements, metals such as nickel and copper, from chemical samples. These separations are important preludes to chemical tests by traditional analytical methods such as thin-film $x$-ray fluorescence, isotope dilution mass spectrometry, and electrochemistry. A significant benefit of improving ion chromatographic separation techniques is that better quantitation will likely result from follow-up ana- 
Iytical instruments. Although ion chromatography has many applications, the NBS/Dionex research will concentrate on improving tests of biological and biomedical samples-for example, determining reliably if toxic levels of nickel or vanadium are contained in biological tissues exposed to fossil fuel emissions.

\section{IRCUIT CHECKS FOR DATA} CONVERTERS SIMPLIFIED

NBS researchers have developed a method that reduces the number of tests needed to ensure reliable operation of digital-to-analog converter (DAC) circuits from 1,024 to as few as 13. These circuits are at the heart of computer-based systems, modern test measurements and diagnostic equipment, and even new home stereo components. The NBS method combines analytical com puter modeling information with actual measured errors obtained from bench testing a number of data converters of the same type. From these two sources, researchers can pinpoint which individual clusters of circuit components require attention in order for the overall data conversion device to operate acceptably. NBS scientists identified 13 calibration points, representing the complex effects of many circuit components, but this number could vary depending on the type of converter circuit. Equipment manufacturers or users could use the simplified strategies of the newer NBS technique to set up a calibration system that would provide measurements of "acceptable accuracy." For further informatıon, contact Barry Bell, B162 Metrology Building. NBS. Gaithersburg. MD 20899. 301/975-2402.

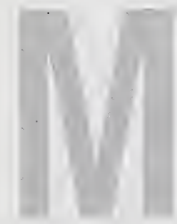

\section{EASUREMENT}

ASSURANCE FOR THE NUCLEAR POWER INDUSTRY

NBS and the Atomic Industrial Forum (AIF) have begun a new measurement assurance program to aid nuclear power facilities in making accurate measurements of radioactivity. The program, conducted by AIF with assistance from NBS, concentrates on operatıonal and environmental radioactivity measurements (not personnel dosimetry) and includes the distribution of blind standard samples for measurement by participants, analysis of the data from the blind tests, calibration services, technical consulting, and direct traceability to NBS standards. Utilities representıng approximately 40 operating power stations and four commercial laboratories which provide radioactivity standards and calibration services for the nuclear industry already participate in the program. The cost of participating in the program is approximately $\$ 10,000$ for the first year. For further information or to enroll in the program, contact David Harward, Atomic Industrial Forum, 301/654-9260. For technical details about the program, contact Daniel Golas, an AIF research associate at NBS 301/975-5540

\section{OINT PROGRAM BEGUN ON LINEWIDTH}

NBS and VLSI Standards, Inc. of Mountain View. California. have begun a joint research program aimed at developing the next generation of linewidth standards for the semiconductor fabrication industry. Linewidths are an important feature dimension on integrated circuits (IC's). They can be as small as 1 micrometer or below. Proper process control requires the fabricator to be able to measure linewidths accurately, but the problem is complicated because the dimensions of these features are approaching the wavelength of the light used to measure them under a microscope. Determining exactly where the edges of the lines are is particularly difficult. The best current linewidth standards - sold as NBS Standard Reference Materials-are for lines on the photomasks used to make IC's and depend on light transmitted through the transparent photomask. (See article on page 15.)

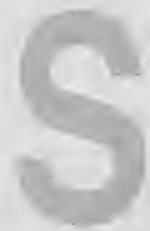

\section{ENSORS FOR NUCLEAR} WASTE CONTAINER CORROSION EXAMINED

Modeling and predicting the long-term effects of corrosion in proposed high-level radioactive waste storage areas is the goal of a program NBS is working on with the Nuclear Regulatory Commission. NBS researchers are studying $\mathrm{pH}$ sensors in simulated environments to determine how well they indicate corrosion processes in nuclear waste containers. These sensors also are useful for indicating possible corrosive action by monitoring the $\mathrm{pH}$ of waterbased fluids in deep-earth nuclear waste storage vaults.

NBS scientists are studying reactively sputter-deposited iridium oxide, a thin-film material that shows promise as an effective $\mathrm{pH}$ sensor because of its ability to operate at high temperatures. This type of sensor also is desirable because its low electrical resistivity and high corrosion resistance eliminate some of the shortcomings of other sensors.

In a concurrent effort, other NBS researchers are evaluating data on corrosion and leaching behavior of various materials proposed for use in nuclear waste containment.

OOPERATIVE PROGRAM TO STUDY ELASTOMER BLENDS ESTABLISHED

NBS and GenCorp, Inc., of Akron, Ohio, have established a joint research program to develop quality control information for the manufacture of tires and advanced elastomer products made from polymer blends. GenCorp researchers are synthesizing samples of butadiene polymers, copolymers, and other elastomeric blends for examination of their microstructures by small-angle neutron scattering (SANS) at the NBS research reactor. The SANS technique, which uses lowenergy neutrons as probes to measure the structures of polymer chains in blends, allows scientists to determine the phase separations of molecules as a function of temperature and composition. SANS measurements will be used by the researchers to develop phase diagrams that will show the mixing and curing times required to obtain specific properties in polymer materials. The joint project is part of the NBS research associate program. which provides an opportunity for people from industry. universities, technical societies, and other organizations to conduct cooperative research at NBS on projects of mutual interest; salaries are paid by the sponsor 


\section{Riding a Heat Wave: \\ Researchers Take Another Look at Superconductivity}

t's not much to look at, akin to a fragment of charcoal. And it has problems-lots of them. But, oh, what a future this material has.

The unglamorous black shard NBS surface scientist Dr. Roger Stockbauer held in his hand could very well be the cornerstone of a technological revolution. That prospect keeps Stockbauer and colleague Dr. Richard Kurtz up nights working at their beamline on the Bureau's Synchrotron Ultraviolet Radiation Facility-II (SURF-II). Their aim: to pin down the electronic structure of this compound of yttrium, barium, copper, and oxygen. The information is essential to determining why this ceramic oxide and related compounds are superconducting at temperatures that only months ago were dismissed as unimaginably high for resistance-free conduction of electricity

"I can't see keeping away from this," says Kurtz. "This is so hot that I can't imagine anything else would be as exciting."

Surface scientist Kurtz is not alone in his enthusiasm. It is shared by the Bureau's physicists, chemists, ceramists, theorists, and engineers-technical experts of virtually every kind that are involved in nearly 20 projects focused on trans. forming the newly discovered hightemperature superconductors from laboratory curiosity to useful technology. In fact, the surprise heat wave in the superconductivity field has overtaken researchers worldwide, including thousands in the United States alone.

Many of these researchers believe they are on the trail of materials that will allow resistancefree passage of electricity at room temperature, as compared with today's conventional, metallic superconductors that are bathed in expensive, cumbersome liquid helium at 4 kelvins (minus $452^{\circ} \mathrm{F}$ ) The technological windfall would be enormous-electric cars, devices for storing electricity generated by power plants during off-peak hours,

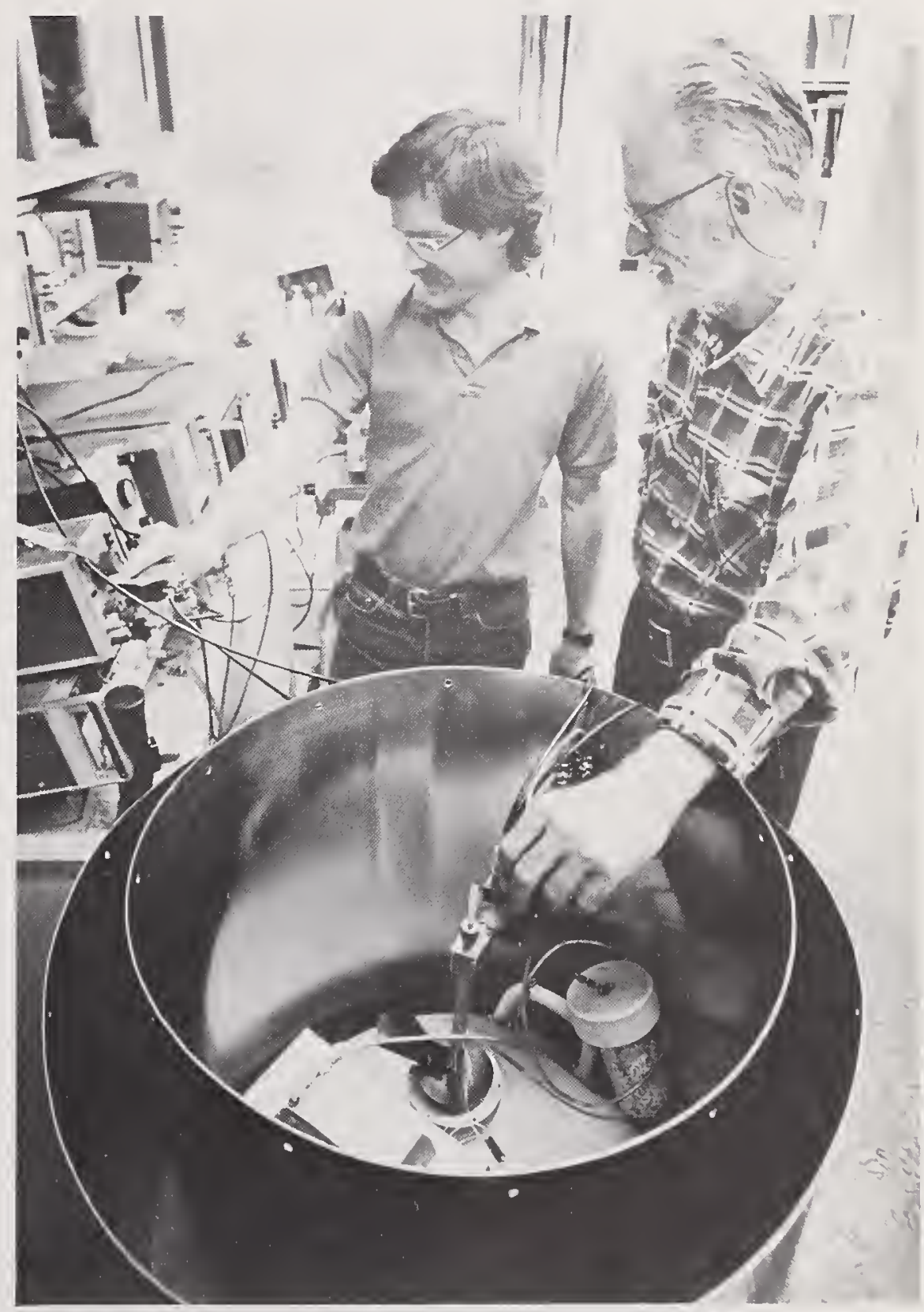

\section{Electronics engineer James Beall (left) and physicist Dr. James Zimmerman adjust apparatus used with the high- temperature SQUID they developed and built. This SQUID may be the first practlcal superconducting devlce to operate in liquid nitrogen.}

magnetic levitating trains that travel at speeds of several hundred miles per hour, dramatically faster computers, and scores of other applications. But even if scientists do not reach their ultimate milestone of a room-temperature superconductor, already available materials that are superconducting at temperatures above that of liquid nitrogen (77 kelvins), a cheap coolant in wide use, promise immense dividends.

The big questions, of course, are can the new high-temperature superconductors fulfill their technological promise and, if so, when? The research program under way at NBS laboratories in Gaithersburg, Md., and Boulder, Colo., focuses 
on helping U.S. industry tap the vast commercial potential of the unusual ceramics.

"The Bureau has been studying and measuring the properties of superconducting materials for more than three decades," explains Dr. Robert Kamper, director of the Bureau's Boulder laboratories and chief of the NBS Electromagnetic Technology Division. "While the new materials hold great commercial promise, the superconductor industry already registers annual sales of about $\$ 200$ million. The measurement standards and methods that support manufacturing and commerce in this industry were developed here. We also have developed several superconducting devices, including what is probably the world's largest working array of Josephson junctions-a series of 14,184 junctions that can produce a precise 10-volt standard of electricity.
"Our expertise and measurement capabilities in areas crucial to exploiting this tremendous opportunity will support U.S. industry's efforts to surmount the many obstacles that must be overcome before the new high-temperature superconductors can be put to practical use."

\section{The Goals}

The Bureau's program, which includes formal and informal collaborations with industry, universities, and other government laboratories, has three complementary aims:

\section{$\square$ Contribute to efforts to} increase the materials' critical current density. For microelectronic uses, such as connecting semiconducting chips in a computer, the materials must reliably conduct currents of at least 100,000 amperes per square centimeter $\left(\mathrm{A} / \mathrm{cm}^{2}\right)$. I_arge-scale

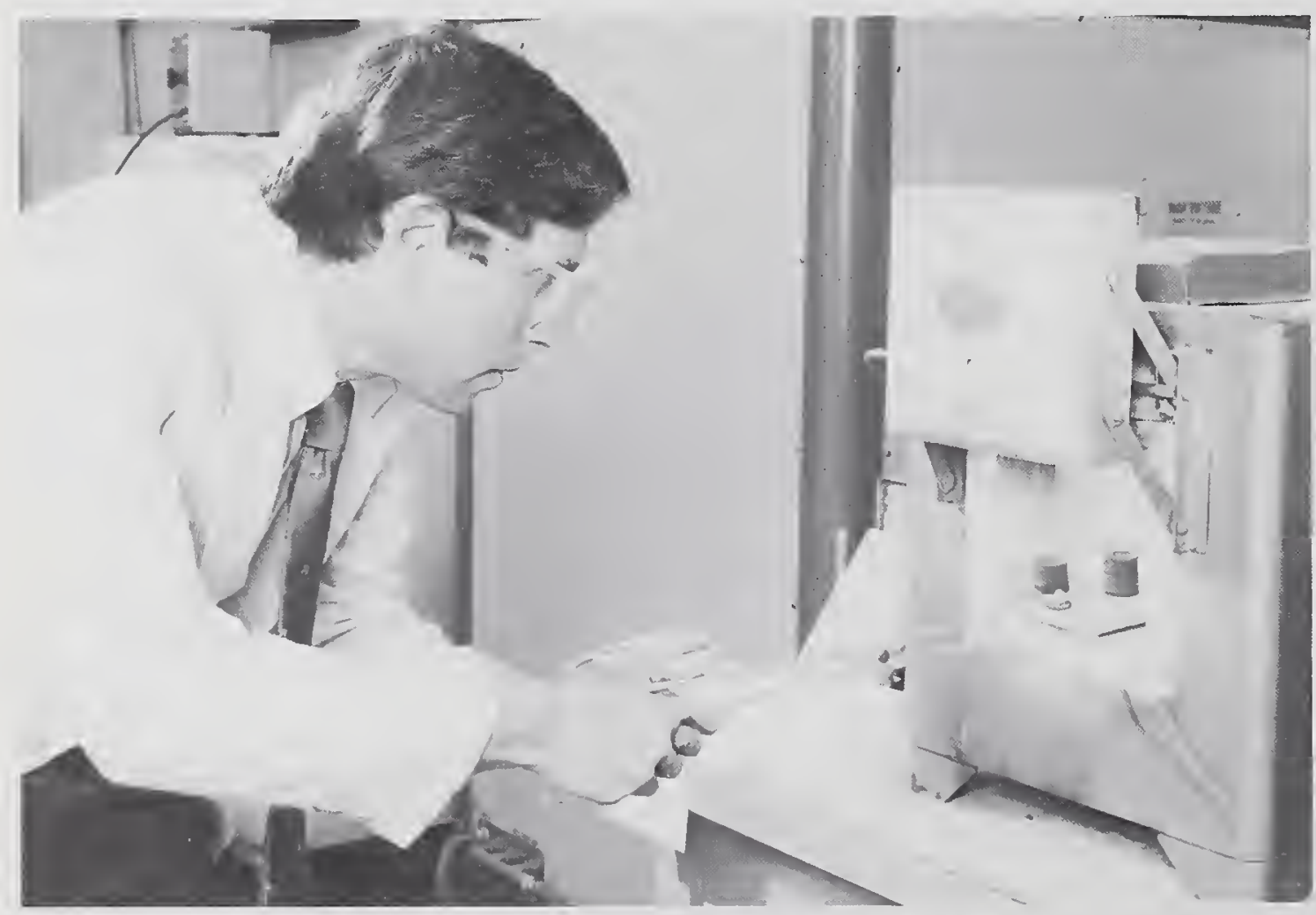

To help make more cost effective and reliable superconductors, Dr. Stephen Frelman and his NBS colleagues are working to determine how processing procedures influence their electrical, magnetic, and mechanical properties. applications, such as electric transmission lines, will require current densities of at least 1,000,000 $\mathrm{A} / \mathrm{cm}^{2}$. Most studies of the hightemperature superconductors report critical current densities of about $1,000 \mathrm{Avcm}^{2}$.

While an overriding concern, the current-density problem encompasses many other difficulties. For example, events at grain boundaries in these polycrystalline materials appear to disrupt the flow of superconducting current. NBS studies will focus on determining and measuring the structural and electronic variables responsible for superconductivity at high temperatures, as well as those that pose obstacles to achieving the desired critical current density.

$\square$ Support development of a theory to explain hightemperature superconductivity. Intuition and trial-and-error methods spawned the discovery that compounds made of almost any one of the rare earths, barium, and copper oxide are superconductive at temperatures that only months ago were deemed unattainably high. Why particular blends of these elements are superconductive is a mystery, however.

Without a guiding theory, researchers racing to overcome the problems that beset the materials already in hand and to develop room-temperature superconductors may find their paths blocked. In collaboration with scientists at other organizations, NBS researchers are working to construct an encompassing theory that accounts for high-temperature superconductivity 
in the ceramic materials. Their efforts are supported by other NBS projects focusing on the materials' structural and electronic properties.

$\square$ Support development and control of processing methods. The new materials are ceramicsbrittle and extremely susceptible to fracture. While some groups, including those at NBS, have fashioned the ceramics into discs, thin wire, tapes, films, or other rudimentary shapes, questions about fabrication techniques abound. Even if researchers solve the current-density problem and others, the materials would have little commercial value if they cannot be made cost effectively and reliably. At this stage, says Dr. Stephen M. Hsu, chief of the Bureau's Ceramics Division, the priorities are "to understand what the material is, how it works, how to make it, how to control it; to identify critical parameters; to develop measurements of these parameters; and to develop standards to help other people make the material."

This fundamental information will support other NBS efforts that are

\section{...the priorities are "to understand what the material is, how it works, how to make it, how to control it; to identify criti- cal parameters; to devel- op measurements of these parameters; and to develop standards to help other people make the material."}

focusing on thin films, which will be crucial to the microelectronics industry, and on the bulk forms that large-scale applications will require. In practice, wires, coils, and other bulk forms are made of combinations of materials-composites containing superconducting fibers embedded in a matrix that compensates for structural weaknesses and inherent instabilities in electrical current. Making a good composite, however, requires evaluating the performance of the entire structure, not just the superconducting fibers. NBS researchers will also characterize the properties and performance of various candidate composites.

\section{Data for Industry}

While the sights of most researchers in the vastly expanded field are set on discovering a superconductor that operates at room temperature, NBS researchers cast themselves in an important supporting role. Explains NBS ceramist Dr. Robert Roth, who developed what is perhaps the most comprehensive phase diagram to guide preparation of the superconducting yttriumbarium-copper-oxygen material,

"We don't want to compete with industry. We want to help them. They want detailed and accurate phase equilibria and other information. We aim to supply data that are useful to industry."

Companies such as IBM, AT\&T, and Westinghouse, as well as the Naval Research Laboratory, universities, and other institutions, regularly send samples of their high-temperature superconductors to the Bureau for careful characterization. Only from this type of detailed evaluation will scientists get a fix on the combination of compositional, structural, and electronic attributes that underlie hightemperature superconductivity. Currently, the compounds that have created such a stir in laboratories and board rooms around the world are not much different from alchemists' creations.

"Superconductivity is a macroscopic phenomenon that is the product of many microscopic and quantum phenomena," explains Dr Alan Clark, of the NBS Electromagnetic Technology Division in Boulder. In other words, there are lots of measurements of physical and chemical processes to be done before researchers fully understand how and why the ceramic oxides work.

\section{Getting to the Heart of the Matter}

Since January, Clark and his colleagues have been zeroing in on many of the subtle details that lie at the heart of high-temperature superconductivity. They began with the lanthanum-bariumcopper-oxygen compound discovered last year by scientists at

\section{"We don't want to compete with industry. We want to help them. They want detailed and accurate phase equilibria and other information. We aim to supply data that are useful to industry.",}

the IBM Zurich Research Laboratory. Although it generated a rather tepid initial response from a skeptical scientific community, that compound, which is superconducting at 30 kelvins, is the source of the current frenzy in the field. When new materials-most notably the yttrium-barium-copperoxygen multi-phase compounds discovered by the University of Houston's Paul C.W. Chu and his colleagues-pushed the superconductivity temperature to nearly 100 kelvins, the group expanded its efforts to describe various properties of the high-temperature superconductors and develop measurement techniques. 
Using sophisticated instruments, Clark and his colleagues make accurate measurements of the critical temperature (the temperature at which electrical resistance vanishes), the critical field (the highest magnetic field the material can withstand without losing its superconductivity), the critical current (the largest amount of electrical current the material can carry), the Meissner effect (the expulsion of external magnetic fields), the energy gap (roughly, the strength of coupling between electrons that pair up to. form a superconducting current), and many other properties.

One of the additional properties is the Josephson effect, the resistanceless passage of current through a thin insulating layer that separates two pieces of superconducting material. In April, Dr. John Moreland and Clark detected the phenomenon in the yttrium-bariumcopper-oxygen material at liquidnitrogen temperature, an observation also made by teams in France, at IBM, and in Japan. Computers based on Josephson junctions, envisioned since the discovery of the phenomenon in 1962, could operate substantially faster than today's supercomputers.

Measurements of the Josephson effect and other properties are providing clues that will help answer the question foremost in the minds of theoreticians: Why do the ceramic oxides superconduct at such high temperatures? The prevailing $B C S$ theory, which describes the mechanisms responsible for the absence of electrical resistance in metallic superconductors, may not apply to the higher-temperature ceramic materials. According to the theory, superconductivity arises when electrons couple and then travel in lockstep fashion, proceeding unimpeded. (In normal conductors, single electrons move randomly, banging into atomic nuclei and other electrons and creating heat, or resistance.) In conventional superconductors, phonons-essentially sound waves generated by the back-and-forth movements of atomic nuclei in the crystal lattice-cause electron pairing. Phonons may not be the key actors in the high-temperature materials, but, while some researchers argue otherwise, the standard theory may still apply, although with some yetto-be-determined twists.

'Our inclination is that the new materials are BCS-type superconductors," explains Clark. "There are indications that there is a very strong coupling mechanism joining the electron pairs together. But what that coupling mechanism is, we really don't know. You have some mechanism that's pulling the two electrons together. Right now it's up for grabs as to what that is.'

The enigma appears in measurements made with the "break junction technique" devised by Moreland at NBS. The method involves placing a bulk sample of a superconductor on a microscope slide and then bending the material and the slide with an electromagnet until the sample breaks, creating a tunnel junction between the split ends. Electrons migrate across the junction, creating a tunneling current that reveals characteristic features of the superconductor.

According to measurements made with Moreland's method,

\section{"Our inclination is that the new materials are BCS-type superconduc- tors," explains Clark.}

the size of the energy gap in the ceramic oxides corresponds to the values predicted by the BCS theory. Some of the other laborato ries doing tunneling measurements have reported higher values. While suggesting that the differences require close study, Moreland says he suspects that the other teams measured two or more energy gaps simultaneously, a hazard posed by the extremely granular nature of the materials. Moreover, Moreland notes that energy-gap measurements are sensitive to the type of technique used, a problem now recognized by researchers.

In addition, the NBS group, again using the break junction method, found evidence for a strong coupling mechanism, much stronger than in metal superconductors. Since results from other laboratories cast serious doubt on phonons as the electron-coupling mechanism, NBS data may reflect the activity of plasmons, excitons, or other subatomic particles that are on the list of potential coupling mechanisms. A clearer picture may emerge from more detailed studies at NBS Boulder laboratories and by researchers using neutron scattering techniques in the NBS Gaithersburg laboratories.

\section{Current Problems}

The ceramic-oxide superconductors also exhibit disturbing frailties. For example, measurements by Drs. Jack Ekin and Ronald Goldfarb, of the NBS Electromagnetic Technology Division, show that the critical current drops off dramatically when exposed to magnetic fields only slightly greater than the Earth's. In bulk samples, the critical current in magnetic fields measuring 100 gauss is only one-hundredth the size of current in a field of 1 gauss. To be useful as magnets, explains NBS physicist Ekin, the ceramic oxides will have to withstand fields of at least 10,000 gauss.

Ekin, who specializes in measurements of critical current density, hypothesizes that the extreme sensitivity of the new superconductors 
to magnetic fields, as well as some other shortcomings, may stem from the disordered arrangement of crystallites, or grains, in the materials. "Our data from studies of bulk polycrystalline samples and IBM's work with epitaxial films," he says, "suggest very strongly that the materials contain strong and weak superconducting regions that are inherent features." Like a chain, the ceramic oxides appear to be only as strong as their weakest link.

What the data indicate is that the superconducting current flows in a preferred direction, moving twodimensionally rather than in three dimensions as in conventional superconductors. If the strong regions are arranged in sequential planes, Ekin speculates, the superconducting current will flow unimpeded from grain to grain. If it is forced to jump to a plane above or below, as by a perpendicularly oriented crystallite, the current drops markedly.

The geometric orientation of crystals appears to be a key variable in increasing the critical current density. The success of IBM researchers in constructing a thin film that passed currents of $100,000 \mathrm{~A} / \mathrm{cm}^{2}$ at liquid-nitrogen temperature stems from their ability to grow large grains, which accommodated the two-dimensional flow of electron pairs.

But can the same geometric order be achieved in bulk materials, as would be required for magnets and other large-scale uses? Ekin believes so. In a recently published paper, he proposed general guidelines for achieving the desired alignment of grains in bulk materials made from powders. With samples provided by collaborators from Westinghouse, AT\&T, Argonne National Laboratory, and the Coors Ceramics Co., Ekin will first test the validity of the hypothesis that grain orientation strongly influences critical current density. If the hypothesis

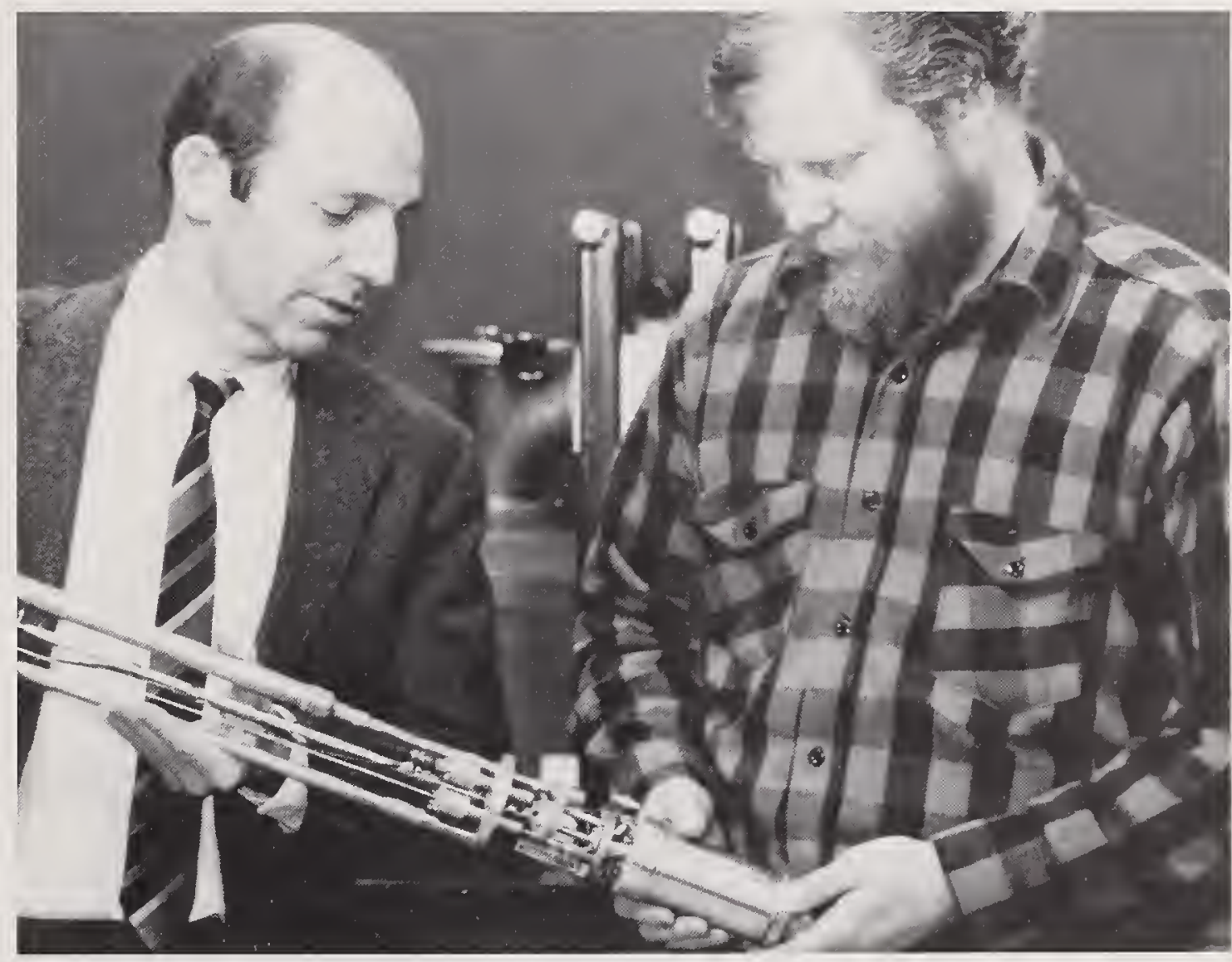

\section{Drs. Alan Clark (left) and John Moreland use a break junction apparatus devlsed by Moreland to make electron tunneling measurements on the hlgh-temperature super- conductors. These measurements will help explaln why the materials become superconductors at high temperatures.}

is confirmed, he will move on to perfecting his proposed methods for aligning the grains.

Another problem, common to all superconductors, is devising a method for "pinning" lines of magnetic flux that would otherwise drive the superconducting current out of the material. "The supercurrent concentrates magnetic flux in regions we call fluxoids," Ekin explains. "The compromise worked out in present-day superconductors is to build in metallurgical defects that immoblize these magnetic-field regions so that the rest of the material is superconducting." Whether the same flux-pinning techniques will work in the hightemperature superconductors is unknown.
Also on the agenda of the researchers in the Electromagnetic Technology Division are measurements of the thermal properties of the ceramic-oxide superconductors. Because heat is the bane of superconductivity, thermal conductivity and other properties are important processing and performance variables. For composites, measure ments of thermal properties determine the volume of copper or other matrix materials needed to conduct heat away from superconducting fibers and avert the runaway spread of electrical resistance. The researchers, who have made some of the world's most precise measurements of stress effects, are evaluating how stresses and strains 
encountered during fabrication or in actual working environments will affect the material's performance.

\section{Studying Thin Films}

Facing many of the same questions and problems, another group of NBS scientists is investigating methods for making thin superconducting films. Here, too, the emphasis is on processing variables. Fabricating thin films, however, introduces special problems, the result of the exacting requirements for making integrated circuits and other microelectronic devices. For example, the films must be of uniform composition and quality, which is influenced not only by technique but by the surface geometry of the substrate explains Dr. Richard Harris of the NBS Electromagnetic Technology Division.

Harris notes that IBM's thin film was deposited on a strontiumtitanate substrate, which has "interatomic spacings comparable to the new materials." Capitalizing on the similarities in atomic geometry, IBM researchers were

\section{In May, the group made what may be the first practical superconducting device operating in liquid nitrogen.}

able to create a uniform film that achieved the current density necessary for microelectronic applications. The accomplishment showed that the desired current density is an attainable goal. One challenge now is to repeat this on a substrate of silicon, the building block of conventional microelectronic devices.

In their thin-film work, Harris and his colleagues are initially concen- trating on techniques akin to the one used by IBM, in which yttrium (or another rare earth), barium, and copper are vaporized simultaneously in oxygen. The vapor is then deposited on a heated substrate. An alternate method, one that is more complicated and more costly, is molecular beam epitaxy. The technique entails growing singlecrystal films, molecular layer by molecular layer, on a crystalline substrate.

"There is a lot of trial-and-error work going on right now," Harris explains. "First, people will probably learn how to make a particular technique work. Then they'll go back to figure out why it works."

\section{Applications for Super- conducting Films}

Once Harris and his colleagues refine their technique for applying thin films, they will move on to the next step of exploring applications, an area where they have considerable experience. Since 1969, the team has been building devices that exploit the unique measurement capabilities afforded by superconducting materials. These devices include microwave mixers that can detect single photons, super fast analog-to-digital converters, and arrays of Josephson junctions that convert a precise frequency to a precise voltage. In fact, the present voltage standard is based on a Josephson junction integrated circuit made by this group with conventional superconducting materials.

In May, the group made what may be the first practical superconducting device operating in liquid nitrogen. Called a SQUID, for superconducting quantum interference device, the simple instrument can measure extremely low magnetic fields, as determined from variations in radio-frequency imped- ance of a superconducting ring containing a single Josephson junction. Built by Dr. James A. Zimmerman, an NBS veteran enticed out of retirement by the superconductivity heat wave, the SQUID was made with a sample of yttrium-barium-copper-oxygen material prepared by colleagues $\mathrm{Dr}$. Ronald Ono and James Beall, and it operated at temperatures up to 81 kelvins, 4 kelvins above the temperature of liquid nitrogen.

One commercial application Harris foresees for superconducting films is as interconnecting strips between integrated circuits in computers. Copper or aluminum wires now do the job, but resistance in the wire limits the overall speed of the computer.

Here, as in other uses envisioned for thin films and bulk superconductors, the problem of achieving good contacts arises. Heat buildup, which can squelch superconductivity, is especially troublesome at connections between superconductors or between superconductors and other materials. Contacts will have to be of extremely high quality, Harris says.

\section{Answering Processing Questions}

One of the paradoxes presented by the high-temperature superconductors is that samples of the materials are easy to make-so easy that even high school students have gotten in on the act. But it's the quality of the samples and, ultimately, the quality of thin-film and bulk superconductors that concern Roth of the NBS Ceramics Division.

"Just because you have a sample doesn't necessarily mean that you have a good superconductor or a good ceramic," he says.

Anyone who has baked a cake can understand Roth's point. Overlook important details in a recipelike the correct oven temperature, baking time, or proportions of ingredients-and the result might 
be edible, but certainly not the appealing creation intended.

Roth's phase diagram of the yttrium-based superconductor is the ceramist's equivalent of a cake recipe. It specifies the proper mix of ingredients-oxides of yttrium, barium, and copper-and the proper heating temperature and time for making pure powder samples of the superconductor. It also depicts the complex interactions among the starting materials

\section{"By varying the amount of oxygen in the material by one part in seven," Rhyne says, "you can go all the way from a semi- conducting state to a superconducting state."}

as the temperature and ratios of the three oxides change. Deviate from the recipe and you could get a mixture of four different compounds, including the superconductor, or the desired phase could be absent.

The phase diagram is also an important starting point for other endeavors that are crucial to understanding the hightemperature materials and for applications. "What people want to know is, at what temperature and what composition is the superconducting phase in equilibrium with liquid so they can make some attempts at crystal growth," Roth says. "And they want to know the effect of liquid and other compositions on making ceramics." While many groups are trying to grow large crystals of the superconductors, which would especially benefit efforts to make thin films, success so far has been limited.
Preliminary results from Roth's $x$-ray diffraction studies suggest why. The studies show that the superconducting compound does not melt directly to a liquid of the same composition, resulting in the formation of unwanted phases. Another obstacle is posed by changes in atomic geometry that occur as the superconducting phase forms in the system. When annealed in oxygen at 500 to $600^{\circ} \mathrm{C}$, the forerunner compound, $\mathrm{Ba}_{2} \mathrm{YCu}_{3} \mathrm{O}_{6}$, oxidizes rapidly to form the superconducting phase,

\section{$\mathrm{Ba}_{2} \mathrm{YCu}_{3} \mathrm{O}_{7}$}

During the transition to the seven-oxygen compound, according to neutron diffraction analyses carried out by researchers in the Bureau's Radiation Reactor Division in Gaithersburg, the crystal symmetry of the material changes. Rather than crystallites composed of unit cells with two equal axes and a third axis of a different length (tetragonal symmetry), the superconducting compound is composed of crystallites having unit cells with three unequal axes (orthorhombic).

"When the material goes through this transition," Roth explains, "the crystallites twin," a phenomenon that distorts the arrangement among the tiny grains and disrupts formation of the uniform, repeating array that characterizes a crystal. "This complicates experiments in crystal growing," he says, "and creates problems in measuring the properties of these materials. This is what we're trying to sort out."

Ideally, efforts to grow crystals could forgo the lower-oxygen compound and begin with the superconducting phase. But that may not be possible. Roth speculates that the seven-oxygen compound is not stable. "At least in practice, you have to make the lower-oxygen compound and then oxidize it," he says.

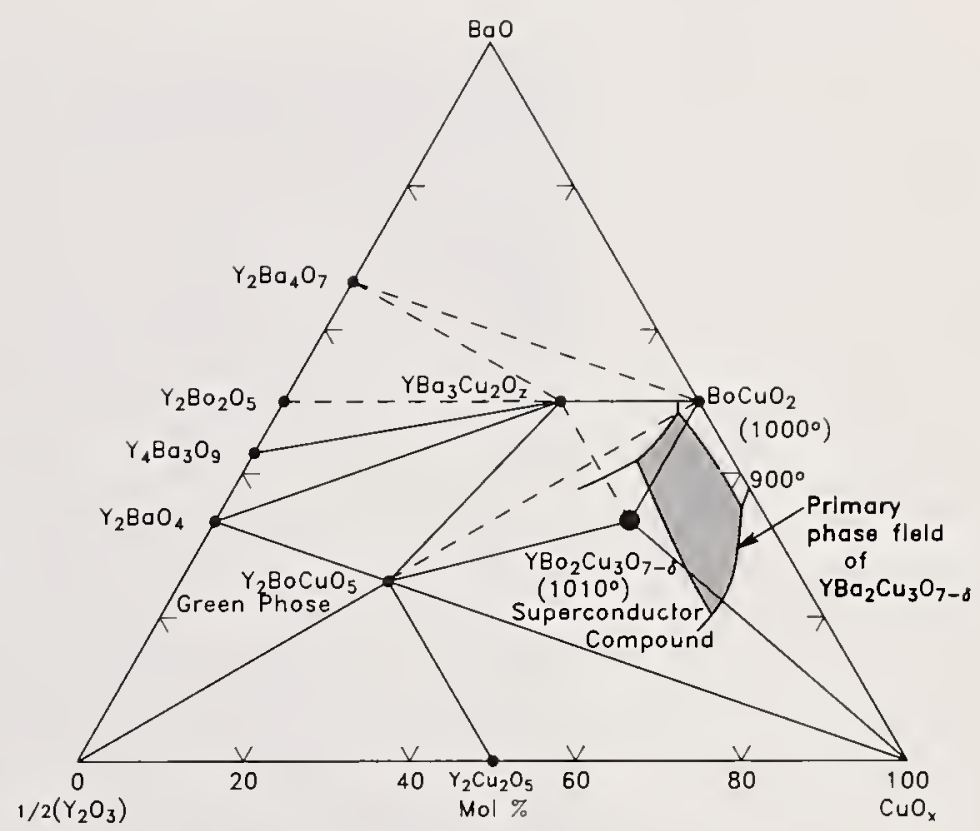

Phase diagrams provide blueprints for ceramic processing. Shown above are the equilibrium phases in the $\mathrm{Y}_{2} \mathrm{O}_{3}-\mathrm{BaO}-\mathrm{Cu} \mathrm{O}_{\mathrm{X}}$ system in air near $1000^{\circ} \mathrm{C}$. The primary phase field shows the range of composition where crystals of the superconducting phase can be grown.

Trying to overcome these difficulties, Dr. Stephen Freiman, also in the NBS Ceramics Division, is using glass-type starting materials, rather than powders, to create crystals of the superconducting compound. "If you have a glass and can pour it you may have a way to make thin films," explains Roth, who is doing $x$-ray diffraction analyses of Freiman's materials.

Much of the ongoing work in the Ceramics Division is related to the question whose answer will ultimately determine the commercial future of the high-temperature superconductors: Can materials of consistent quality be manufactured economically? To answer that question, the division's research teams, working with other NBS experts, aim first to determine how processing procedures influence the materials' electrical, magnetic, and mechanical properties. 


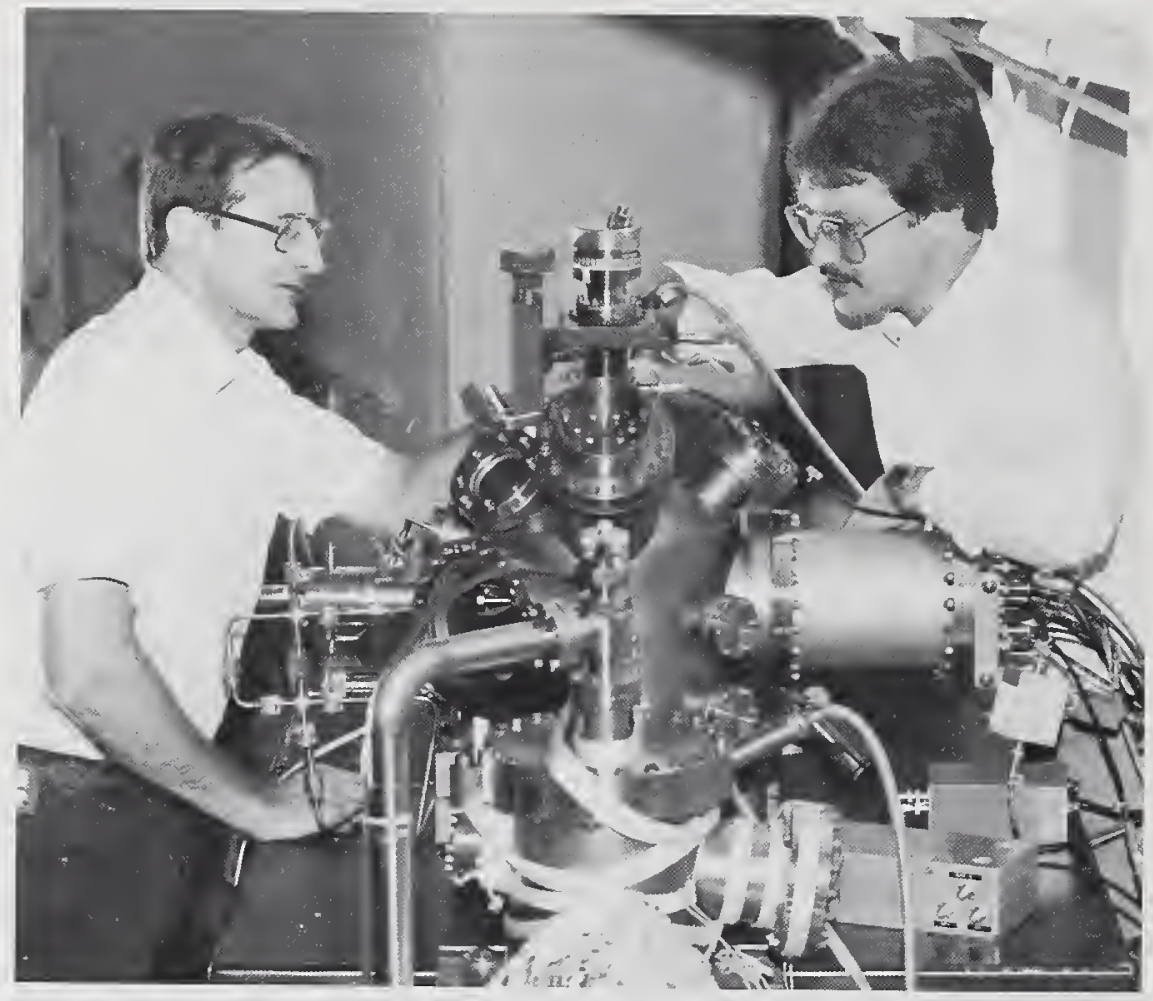

Drs. Roger Stockbauer (left) and Richard Kurtz are using the Bureau's Synchrotron Ultraviolet Radiation Facility-II to study the electronic structure of the new ceramic superconductors.

"Our work to date," says Freiman, "has shown that the transition temperature, as well as the percentage of a sample that undergoes the transition to the superconducting phase, is very sensitive to the temperature and environment under which the material is sintered and annealed. Achieving the necessary level of critical current density in these bulk superconductors will be determined by our ability to tailor their chemistry and microstructure."

But achieving the desired critical current density will not remove all the hurdles that stand in the way of superconducting electrical transmission lines and other large-scale applications. "These materials are relatively fragile, even in comparison to other ceramics," Freiman explains. "Their use in wires and coils, for example, will require that we make them less susceptible to brittle fracture."

\section{Studying Structural Details}

Some of the puzzling structural aspects of the high-temperature superconductors are coming under the scrutiny of Bureau researchers who are using neutron-scattering methods. "Neutrons 'see' oxygen atoms very strongly," explains Dr. James J. Rhyne of the Reactor Radiation Division. This capability is especially important because the oxygen content of the ceramic oxides seems to underlie their high-temperature superconductivity. "By varying the amount of oxygen in the material by one part in seven," Rhyne says, "you can go all the way from a semiconducting state to a superconducting state."

Working at the Bureau's research reactor with collaborators from AT\&T Bell Laboratories, Dr. Antonio Santoro and colleagues in the Reactor Radiation Division determined the positions of the oxygen atoms in the basic units, or building blocks, of the yttriumbased superconductor. It turns out that oxygen atoms can be absent at specific sites. The basic units are composed of layers of copper and oxygen atoms, barium, and yttrium. Depending on the heat treatment, the average number of oxygen atoms in a unit cell can range from six to seven. As determined by the NBS team and by researchers elsewhere, the vacancies occur in one of the copperoxygen layers, forming a chainlike sequence that may be related to the mechanism responsible for superconductivity.

The oxygen site in question "has a very large vibrational amplitude," Rhyne says, "and this might be correlated with the fact that this is where the vacancies in oxygen appear." This evidence, in turn, provides some support for phonons as the electron-coupling mechanism.

Using the method known as inelastic neutron scattering, Rhyne and his colleagues are mapping the vibrational energies of the atoms in several of the rare-earth superconductors and slightly dissimilar materials that are not superconducting. "This tells us about the forces involved in exciting given atoms into discrete vibrational states," Rhyne says. "By measuring the distribution of energies, one hopes to get information about the 
possible phonon mechanisms causing superconductivity."

Many agents for pairing electrons have been proposed, however. Identifying the actual mechanism will require "correlating a large mass of data gathered with various techniques along with theory," Rhyne says

\section{Data for Theorists}

With SURF-II and a vast array of characterization techniques at their disposal, Kurtz and Stockbauer, of the NBS Surface Science Division, believe they can help pin down the answer, feeding important information about the materials' electronic structure to theorists. Results of experiments conducted so far testify to the unusual nature of hightemperature superconductors. One finding, supported by evidence from other laboratories, is that the overall electronic structure of the materials apparently does not change as they become superconducting.

"We were hoping to see a large change in the electronic structure as the material became superconducting, a change that could sup-

\section{Results of experiments so far testify to the unusual nature of high- temperature super- conductors.}

port a new theory," Kurtz says.

"But we saw no change as we cooled the sample and so cannot rule out the old theory."

Kurtz and Stockbauer, who collaborate with colleagues from the Naval Research Laboratory, have used a method called resonant photoemission to identify the electronic states in the yttrium-based superconductor, information that can be used to calculate the energy bands in the compound. According to the theory, electrons in a solid can have a range of energies. If they know how electrons are distributed within different energy ranges, or bands, and how easily electrons can travel between bands, theorists can predict the electrical properties of a material.

"Theorists who try to calculate electronic structure end up with bands due to the different chemical components (in the superconductor)," Kurtz explains. "They can compare directly their theoretical understanding of the material with our measurements."

Once again, experimental evidence suggests that the hightemperature superconductors contradict the conventional wisdom

"The calculations to date do not agree with what we're seeing," Stockbauer says. "So the theorists aren't quite on the right track yet, as far as understanding interactions in the materials."

\section{Formulating a Theory}

The surface scientists' findings are especially intriguing to theorist Dr. David R. Penn, a member of the NBS Radiation Physics Division. To Penn, the resonant photoemission studies suggest that the interaction between electrons in the yttriumbased superconductor is much larger than expected. If the force of the interactions between electrons "is roughly the same as the width of the band structure," Penn says, "then the band structure calculations aren't going to work well. The question then is, what are the electronic states of these materials?"

Supplied with data by Kurtz and Stockbauer, Penn and Dr. Steve Girvin, of the Surface Science Division, intend to use a technique called "cluster calculations" "to interpret the confusing results of resonant photoemission experiments. "We hope to be able to understand the chemistry of these materials at a fundamental level," Penn says.

Then there is the ever-present question that dogs all theorists in the field: What causes electron coupling in the high-temperature superconductors? By Penn's count, at least two dozen explanations have been proposed, including one he and Dr. Marvin Cohen, a theorist at the University of California in Berkeley, are suggesting. They postulate that the pairing results from an electronic excitation, as observed previously in certain transition metals. More important, evidence for the excitations, which Penn and Cohen speculate are caused by two vacant electron positions in the same atom, was found by Kurtz and Stockbauer in their photo emission studies of the yttriumbased superconductor.

In rough terms, the theorists suggest that one electron polarizes an atom, thereby attracting the second electron to form a pair. According to Penn, the hypothesis is a variation of the BCS theory. He and Cohen are now testing the validity of their ideas, using mathematical models

"I would say that anything you propose at this point is very far out almost by definition," Penn says.

"In a month or two, we should know whether our ideas are plausible."

by Mark Bello

Washington, D.C.-area

Science Writer 


\section{President Reagan Announces Superconductivity Initiative}

n July 28, 1987, at the Federal Conference on Commercial Applications of Superconductivity, President Reagan announced an 11-point initiative to promote further work in the field of superconductivity and to ensure U.S. readiness in commercializing technologies resulting from recent and anticipated scientific advances.

The superconductivity initiative includes both legislative and administrative proposals. The major legislative components would: (1) amend the National Cooperative: Research Act to expand the concept of a permissible joint venture to include some types of joint production ventures; (2) amend U.S. patent laws to increase protection for manufacturing process patents; and (3) authorize federal agencies to withhold from release under the Freedom of Information Act commercially valuable scientific and technical information generated in government-owned and -operated

\section{The Department of Commerce will establish a Superconductivity Center at NBS laboratories in Boulder, Colorado.}

laboratories that, if released, will harm U.S. economic competitiveness.

The primary administrative proposals:

$\square$ Establish a "Wise Men" Advisory Group on Superconductivity under the auspices of the White House Science Council to advise the Administration on research and commercialization policies

$\square$ Establish a number of "Superconductivity Research Centers' (SRC's) and other similar groups that would conduct important basic research in superconductivity and serve as repositories of information to be disseminated throughout the scientific community.

The Department of Energy (DOE) will establish three SRC's, as well as a computer database. They are Center for Superconductivity Applications at the Argonne National Laboratory; Center for Thin Film Applications at the Lawrence Berkeley Laboratory; Center for Basic Scientific Information at the Ames Laboratory; and Computer Data Base on Superconductivity at the DOE Office of Scientific and Technology Information.

The Department of Commerce (DOC) will establish a Superconductivity Center at the National Bureau of Standards laboratories in Boulder, Colorado. The center will focus on electronic applications of high-temperature superconductivity

The National Aeronautics and Space Administration is establishing a coordinating group on superconductivity activities at its Office of Aeronautics and Space Technology

The National Science Foundation (NSF) will augment its support for research in high-temperature superconductivity programs at three of its materials research laboratories. In addition, NSF is initiating a series of "quick start" grants for research into processing superconducting materials into useful forms including wires, rods, tubes, films, and ribbons.

The Department of Defense (DOD) is developing a multi-year plan to ensure use of superconductivity technologies in military systems as soon as possible. DOD will spend nearly $\$ 150$ million over 3 years to define the engineering parameters of high-temperature superconducting materials; develop the required processing and manufacturıng capabilities; and accomplish the necessary development, engineering, and operational prototype testing of superconductors. $\square$ Urge all federal agencies to implement quickly the steps outlined in Executive Order 12591 designed to transfer technology developed in federal laboratories into the private sector and encourage federal, university, and industry cooperation in research.

\section{Direct NBS to accelerate its efforts to develop and coordinate standards...in the United States and internationally....}

Direct the Patent and Trademark Office to accelerate the processing of patent applications and adjudication of disputes involving superconductivity technologies when requested by the applicants to do so

$\square$ Direct NBS to accelerate its efforts to develop and coordinate common standards (for example, measurement methods, Standard Reference Materials, and supporting technical data) in the United States and internationally for superconductors and related devices.

$\square$ Encourage federal agencies to continue to reallocate FY 1987 funds into superconductivity basic research, applied research in enabling technologies, and prototype development. Agencies are to place a high priority on this area in FY 1988 and FY 1989.

$\square$ Request that DOD accelerate prototype work in sensor, electronic, and superconducting magnet-based military applications and that DOC (NBS) accelerate development of prototype devices in detection and measurement of weak magnetic fields.

$\square$ Seek reciprocal U.S. opportunities to participate in Japanese government-supported research and development, including superconductivity. 


\section{Life on the Edge: Measuring Linewidths}

The problem of how to measure the width of lines on a semiconductor photomask is a classic example of how NBS responds to industrial needs.

inewidth. A code word for one of the perennial battlefields of the highly competitive integrated-circuit industry.

The National Bureau of Standards produces new measurement technology, and the story of the development of a system for linewidth measurement offers not only a textbook case of product devel- opment, but an insight into how this national laboratory works.

The widths being measured are of circuit lines and other features on the photomasks used to make the electronic devices on integrated circuits (IC's). These lines, and all other features on an integrated circuit, are small and getting smaller. Simple economics rule: The smaller the IC's, the more you can make at a time, the lower the cost per unit Today industry leaders are talking in terms of dimensions less than 1 micrometer wide. A typical human hair is 75 to 100 micrometers wide

The width of $\mathrm{IC}$ features is a critical factor, because it is one of the smallest important dimensions

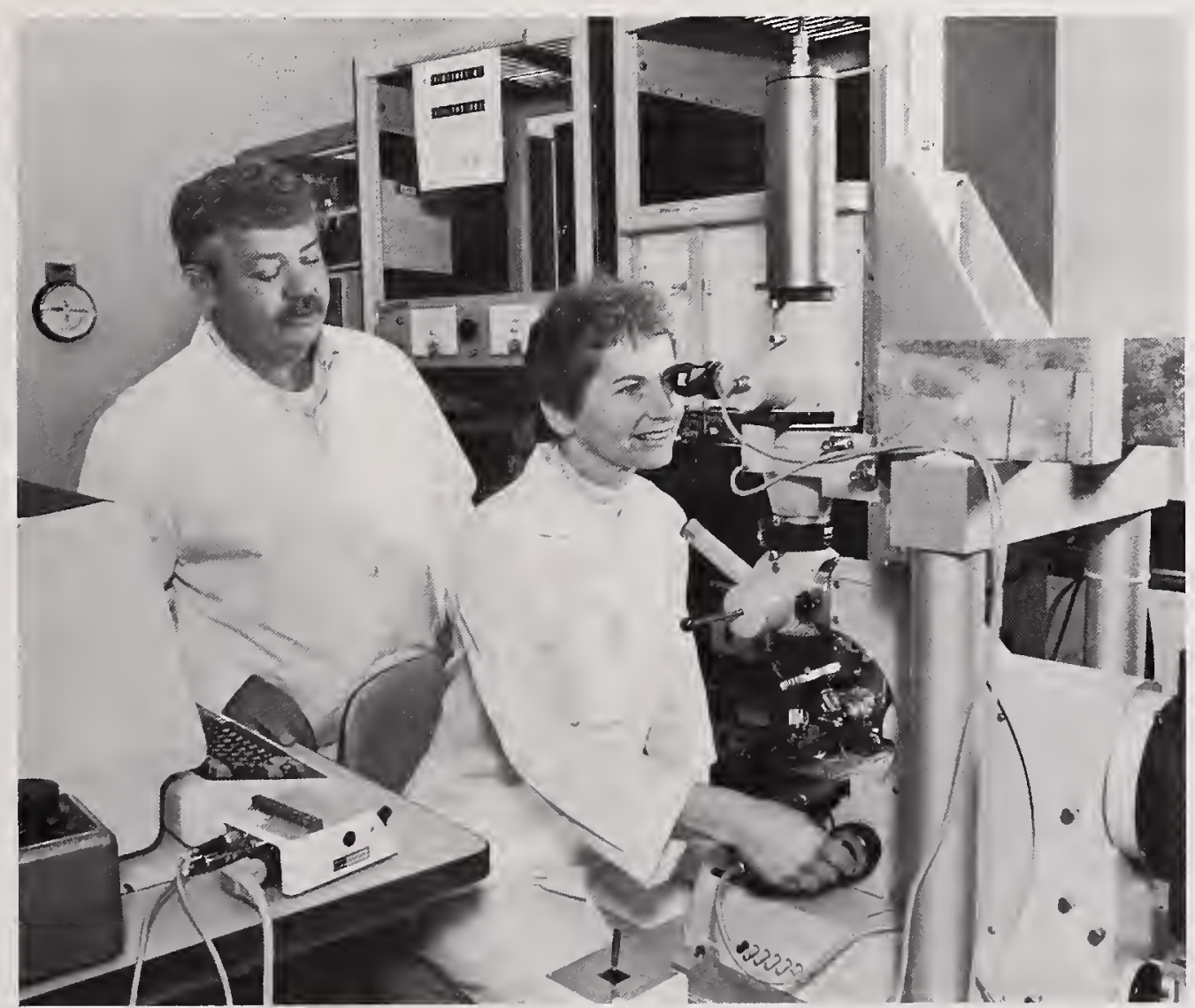

NBS scientists Carol Vezzetti and Sam Jones use a modified optical microscope linked to a data-collection computer to calibrate NBS photomask SRM's. It takes up to a week to calibrate a single photomask-an automated system under development will cut that down to a day.

on the chip, the "minimum feature size," the limit of the manufacturer's ability to control the manufacturing

The problem came to the attention of NBS researchers when a commercial standards maker came to the Bureau seeking measurements to check his linewidth standards against NBS standards.

process. Bad things happen when feature size cannot be controlled Conductive lines may overlap, causing short circuits; they may be broken or pinched ("mousenips, the trade calls it); IC's may not work at all; or, worse yet, they may fail unpredictably in service.

In the early 1970's, the IC industry became aware that there was a problem, somewhere, with the control of critical dimensions. Integrated circuits were being made in a process akin to photography or lithography. The various layers of the circuit are defined by transparent "masks," the equivalent of photographic negatives. Mask suppliers and IC manufacturers couldn't agree on their measurements of linewidths.

The problem came to the attention of NBS researchers when a commercial standards maker came to the Bureau seeking measurements to check his linewidth standards against NBS standards. Dr. Diana Nyyssonen, of the original NBS research team, recalls, "The problem was that there were no NBS standards at those dimensions. In industry, everyone had their own in-house standards, and none of them agreed."

Bureau researchers found that they could not make the measurements at the required degree of 
accuracy because light diffracted around the edges of the lines, making the image seen in the microscope different from the actual lines (see illustration). The pitch of a pair of lines, the distance from the center of one line to the center of the other, could be measured easily, but a measurement that depended on knowing exactly where the edges of the lines were-either the width of the line or the width of the space between lines-was impossible to make to any reasonable accuracy.

The obvious question to NBS researchers was, "If things are that bad here, what is it like elsewhere?" They followed up with about a year's worth of interviews with Silicon Valley firms and reviews of published data

The problem was bad, and it was no secret. Industrial measurements were wildly inconsistent. with errors as great as 20 percent on comparatively large 5-micrometer lines. The popular theory was that there were problems with the optics used to produce the masks and IC's. That the problem might be in the measurement process rather than the production process had not occurred to very many people.

In fact, the NBS team decided, the problem lay with measuring the width of lines on the $\mathrm{IC}$ photomasks. The diffraction effects of light around the edges of the lines was sufficiently great that it was largely a guess as to where the edge was. Not surprisingly, different people made different guesses.

Once the true problem was in sight, the next step was to define it more exactly. The NBS researchers worked closely with their industrial counterparts to make sure that they had a firm understanding of the situation in the "real world." Lists of error sources were drawn up, and mechanical and optical measurement experts at the Bureau argued possible solutions. In the

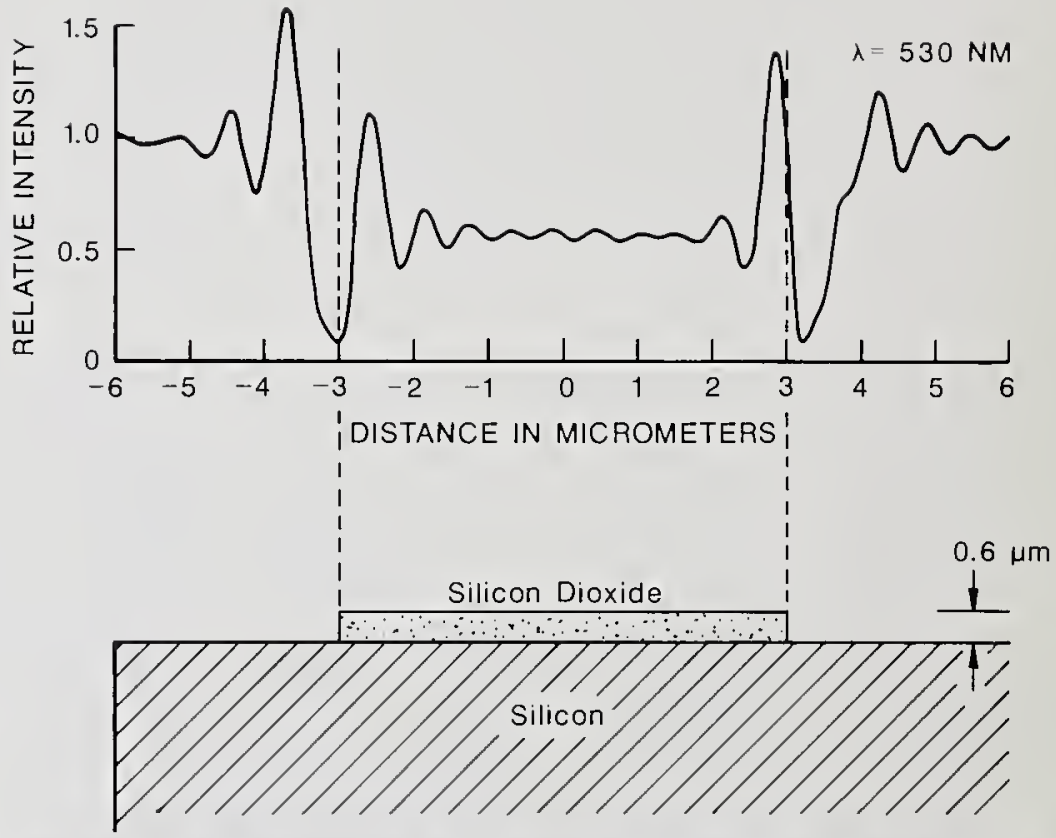

Typical data showing an image of reflected light from a silicon dioxide feature on a silicon base demonstrates the measurement problem. The indicated line edges are only estimated. Based on the data, the left edge probably lies somewhere between $\mathbf{- 4 . 5}$ and $\mathbf{- 1 . 5}$, but an accurate theoretical model is needed to say just where the edge is relative to the complicated reflectivity curve.

end, a decision was made to create a new measurement reference-an artifact that mimicked the photomasks used in industry

The creation of a whole new measurement system is a more complicated undertaking than is generally appreciated, according to Dr. Robert Larrabee, who now manages this project for NBS "It's not enough to provide a good ruler," says Larrabee, "you must understand the physical effects that take place during measurement, the interactions between instrument and specimen-you must understand what it is that you are actually measuring. You must know how to calibrate the instrument used to measure the reference standard.
You must be able to specify the appropriate procedures and tools used in the field. so that the standards will be used properly, as well as the type and size of errors to be expected. And you must communicate these procedures and requirements to the people who will be making the measurements."

Beginning in 1975, various research groups at NBS attacked these problems. Theoretical models were developed, largely by Nyyssonen, to explain how an optical microscope would respond to light diffracting around the edges of a line on a photomask. Amazingly enough, considering the age of optical science, this work resulted in some fundamental discoveries in optics. Textbooks were rewritten.

Comparisons were made with optical and scanning electron 
microscopes: The latter were rejected as the primary measurement tool because the interactions between specimen and instrument were not understood as well as for optical microscopes.

A standard photomask was designed using typical industrial materials and a pattern designed for measurement purposes. A new type of precisely controlled microscope stage was designed and constructed. A photoelectric micro scope system that partially automated the measurement process was designed and built. Instrument set-up and operation procedures were developed. A standard technique, which would in time become an ASTM voluntary industry standard, was developed.

Throughout the whole procedure the research staff stayed in touch with their industrial contacts, reporting progress and soliciting comments. "We had a mailing list of about 1,000 names," recalls Nyyssonen, "and every one represented a personal contact by someone on the staff.

By 1978, NBS had a photomask linewidth standard ready for test marketing. As any good salesperson knows, however, it is not enough to have a great product. You must convince your customers that they want it.

A "round robin" of 10 companies, including $1 \mathrm{C}$ manufacturers, photomask makers, and instrument makers participated in a linewidth measurement trial using the prototype standard and their own measurement procedures. The reported values for a line 2 micrometers wide ranged from 1.5 to 2.5 . This helped convince people that there was a problem.

A year later, NBS issued the final design of its first linewidth standard as SRM (Standard Reference
Material) 474. Because of the painstaking calibration procedures required to certify each copy, SRM 474 was the most expensive reference standard ever produced by NBS- $\$ 5,016$ per unit. It was issued with some trepidation, but went to the best-seller list almost immediately. Demand has exceeded supply almost continuously since the first announcement.

To provide customer support, NBS instituted a series of "Linewidth Measurement Seminars," week-long programs conducted by Nyyssonen and her staff, which featured both lectures and "handson" use of the SRM. Recognizing the importance of the new system, photomask instrument makers loaned commercial measuring equipment to the seminars so attendees could practice on the same microscopes they would use at work. Almost every seminar was booked up weeks in advance.

Information at these semınars flowed two ways, according to Nyyssonen, "We would have feedback sessions at the seminars on what measurement problems the participants were seeıng in their work. Other than the visits to companies, I think the linewidth measurement seminars were our most important source of information. People were very open with us, taking us into their facilities to see their equipment and discuss their problems."

By 1981, Bureau researchers were considering improvements. SRM 474 was expensive largely because it was complicated and took a long time to certify. Discussions with industrial customers revealed that most people really didn't need all the complexity.

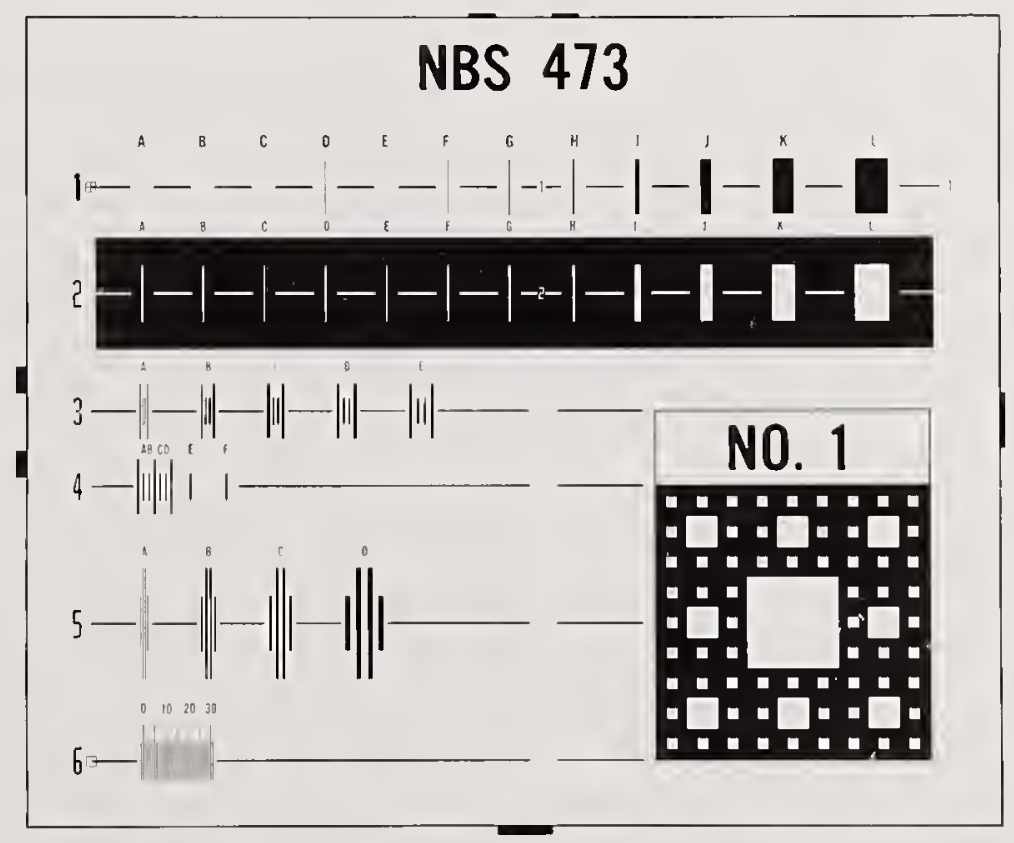

The next NBS photomask reference standard wili be NBS 473, shown here. It will inciude calibrated linewidths as narrow as 0.5 micrometer (Instead of 0.9 micrometer) and as wide as $\mathbf{3 0}$ micrometers (Instead of 10 micrometers). The wider fines are used to calibrate oversized photomasks used In some facifities. 
SRM 475 was designed, a simplified standard that could be certified and sold for much less. (On October 1, 1987, SRM 475 will be priced at $\$ 3,781$.) The NBS masks used a dark chrome to reduce reflections, but some customers use bright chrome masks so a bright chrome SRM was developed and will be released as SRM 476.

Industrial response was gratifying. In 1982, a U.S. firm, one of the world's largest IC manufacturers, formally instituted an inhouse measurement system based on SRM 474. "It has basically become our bible," noted the linewidth measurement project manager. "We've created a whole series of secondary standards, sent them out to the 'front ends' and our measurement squabbles have been cut by 90 percent. I can't remember the last time anyone tried to challenge our readings on a linewidth based on our knowledge from your measurement seminars and SRM 474 whereas that was a weekly if not daily occurrence before then."

Another firm estimated in 1983 that it had invested about $\$ 400,000$ in new measurement procedures built around the NBS linewidth standard and "bought that back many times over" in reduced production problems.

In 1982, NBS studied the impact of the linewidth standard on the semiconductor industry. A hypothetical company making $\$ 1,000$ photomasks would save about $\$ 179$ per mask by using the NBS technology, of which at least half the savings could be directly attributed to the NBS work. Implementation costs: \$2 per mask

On worldwide mask sales of $\$ 375$ million per year, that translates to a $\$ 30$ million savings directly attributable to the NBS program, which costs less than
$\$ 400,000$ per year.

The numbers are to be taken cautiously - too many estimates are involved to be sure of the actual doilars-but almost every variation in the basic assumptions resulted in significant economies.

Technology, of course, does not stand still and neither can a standards laboratory. Today NBS is looking to the 1990's and a whole new set of linewidth measurement problems. The current optical system used to calibrate the NBS linewidth SRM's is useful for linewidths down to about 0.5 micrometer, but manufacturers are beginning to think in terms of

0.1-micrometer linewidths. Accurate measurements at that level will require scanning electron microscopes, with characteristics quite different from optical instruments.

"What happened in optics is what is happening now in scanning electron microscopy." notes

\section{On worldwide mask sales} of $\$ 375$ million per year, that translates to a $\$ 30$ million savings directly attributable to the NBS program, which costs less than $\$ 400,000$ per year.

Larrabee. "People have instruments and are making measurements that they believe are correct. When things go wrong, they don't question the measurement, just the results."

In addition, the present system relies on measuring light coming through a transparent mask. Industry needs a similar standard for measurements made on the opaque semiconductor wafers themselves, and this introduces a whole new set of problems. Imag ing in reflected light can be more complicated to model than imaging in transmitted light, and the mathematical models developed for SRM 474 do not apply to features on integrated circuits.

NBS researchers are looking for solutions to these problems, working as usual with their privateindustry counterparts. NBS currently has formal agreements for joint research with several private firms, including:

$\square$ CD Metrology Inc., to develop mathematical models to interpret the profiles of features as imaged by electron and optical micro scopes;

$\square$ EDAX International, to develop linewidth calibration techniques for scanning electron microscopes

$\square$ E. Fjeld Company, to develop precision stages for SEM's;

$\square$ Hewlett-Packard, to develop state-of-the-art masks for linewidth standards; and

$\square$ VLSI Standards, Inc., for basic research to model how light reflects from thick lines on silicon wafers.

The linewidth standard is just one of many measurement problems studied at NBS, but it is an example of the way the system is supposed to work.

Comments NBS Director Ernest Ambler. "Behind each SRM, each individual calibration, or each table of reference data is a substantial investment in time and effort by our best people. In this case, industry thought that all they needed was an SRM, but in fact they needed an entirely new measurement technology. We have the expertise to know the difference and to solve the problem, and it is our mission at the National Bureau of Standards to do so-it is what we are all about."

by Michael Baum NBS Public Affairs Specialist 


\section{Thin-Film Thermocouples Designed for Diesel Engine Research}

ore efficient and longer-lasting diesel engines may result from the application of a novel type of device developed at the National Bureau of Standards that monitors critical internal temperatures of diesel engines.

Researchers at the NBS Center for Chemical Engineering are experimenting with thin films of noble, chemically inactive metals such as platinum and gold, which are fashioned into scaled-down thermocouples. Unlike traditional wire thermocouples, the thin films are deposited directly onto engine parts and act as sensors to indicate temperature at those points.

By having accurate temperature measurements during operation of such diesel engine components as valves, cylinder heads, and piston crowns, it is possible to monitor wear and tear of engine hardware as well as provide input for controlling automatic engine functions such as fuel-air mix and timing.

Temperature data also are important in the design phase of modern ceramic-coated diesel engines. For example, knowing how hot the combustion chamber of an engine gets during operation allows design engineers to decide how thick the engine's insulating ceramic coating should be or what porosity the coating should have.

Much of the NBS work to datewhich is supported by the Department of Energy - has focused on problems that interfere with successful operation of the films. One of these has been a difficulty with electrical shorts through the material that insulates the film from the surface of engine parts. Poor adhesion of the thin film to the insulator can cause difficulties as well.

"We've made considerable progress in removing some of the problems that exist with thin films," says Dr. Kenneth Kreider, chief scientist on the project. "For example, we've developed a double-oxide layer that includes a thermal oxide and a sputter-deposited oxide which have the best electrical insulating properties at 2000 degrees Fahrenheit." Kreider adds that this material insulates platinum and other metals at engine temper atures and provides improved adhesion

Thin films have many advantages over traditional wire thermocouples. These older devices-basically two wires of dissimilar metals joined at both ends which indicate temperature by measurement of the voltage difference between the two endstend to be cumbersome for diesel

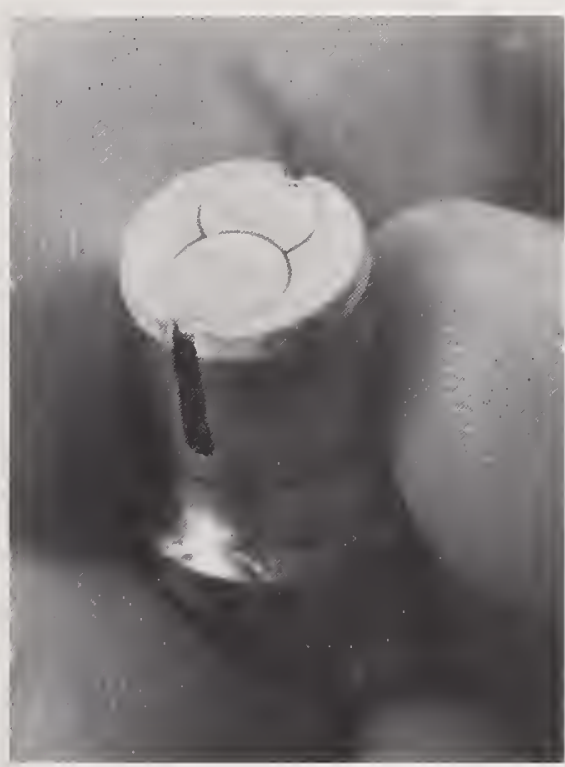

The two discs at the top of this sensor plug are part of a thin-film thermocouple system that will accurately measure the internal tem. perature of a diesel engine.

engine applications. Because the wire devices must be imbedded in machined grooves inside engine parts, they create obstructions. This can lead to distortions in reproducing exact heat transfer conditions

Thin films, on the other hand, use the same principle as wire thermocouples, but typically are only 2 micrometers thick, so they do not cause these interferences. Temperature measurements by means of voltage readings can be made with a voltmeter outside the engine, or perhaps in the future through a readout on a vehicle dashboard.

Thin films have other advantages:

$\square$ They conform to complex surfaces, making them adaptable to a variety of locations inside engines.

$\square$ Multiple installation is easy and inexpensive. Though metals like platinum and gold are used, such a tiny amount is required, the cost is only about $\$ 2$ per thermocouple.

$\square$ Thin-film devices have fast response times.

Besides measuring temperature, thin films also indicate heat transfer, or the amount of heat dissipated by engine operation. This is particularly important in developing modern ceramic diesel engineswhich have no radiators-because accurate heat transfer is the key to efficient operation of these engines.

The NBS work, while showing much promise in laboratory experiments, has moved closer to practical applications. Most notably, it has been used in a ceramic diesel research engine located at Purdue University in Lafayette, Indiana. This research, which is also sponsored by the Department of Energy and the National Aeronautics and Space Administration, aims to develop a fuel-efficient, highperformance engine that could be used in vehicles such as trucks, buses, heavy equipment, and even military tanks.

Kreider also has assisted major diesel engine manufacturers such as Cummins, Detroit Diesel, and Caterpillar, which are exploring how they can use thin-film technology in their products. For additional information, write or call Dr. Kenneth Kreider, B312 Physics Building. NBS, Gaithersburg, MD 20899 301/975-2619

by John Henkel

NBS Public Affairs Specialist 


\section{Concrete Research at NBS: New Ways to Understand an Old Material}
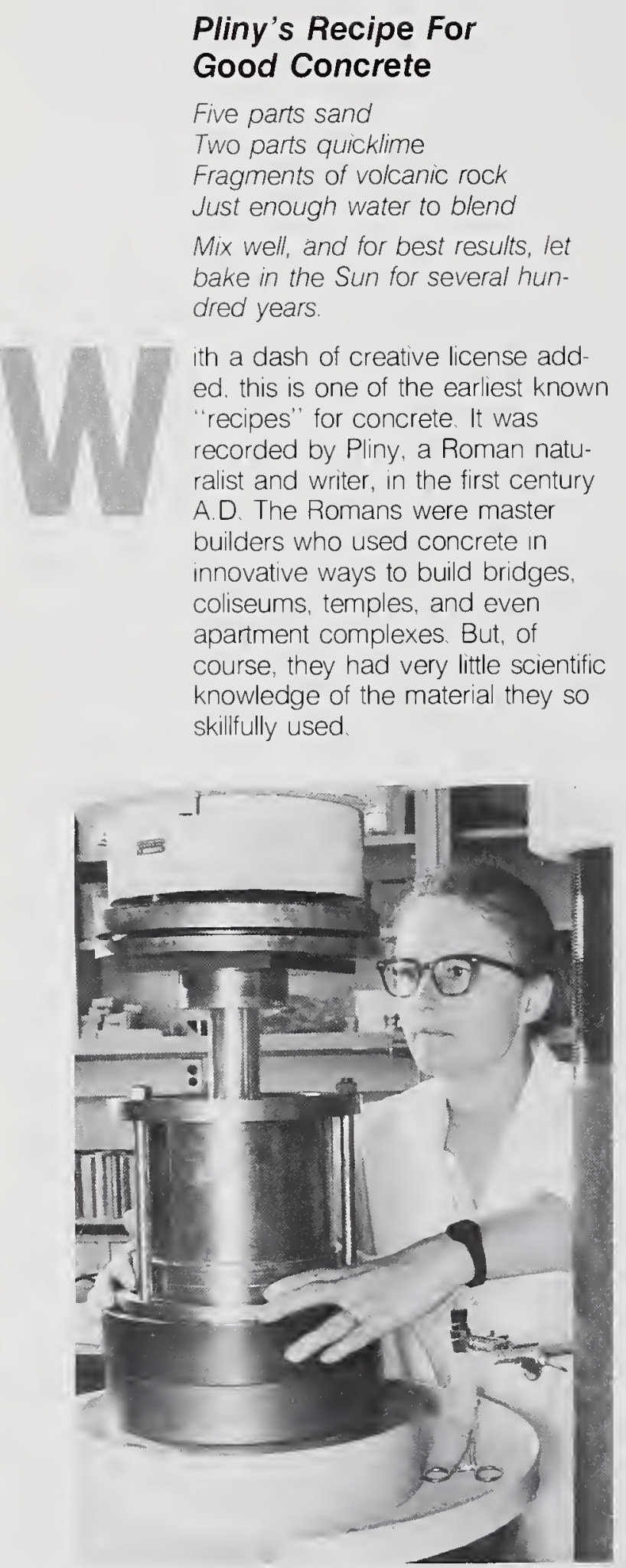

Dr. Leslie Struble uses a cylinder and piston device to study the causes of concrete failure.
In some ways, not a lot has changed. For the most part, concrete is still made with similar basic ingredients - a bonding material (the Romans used quicklime, today it is usually portland cement), an aggregate like sand or gravel, and water. And, despite its great importance and long history as a building material, much is still not known about the behavior of concrete or the factors which control its strength and durability

In the United States alone, billions of dollars are invested annually in millions of tons of concrete used to build skyscrapers, highways, dams, and bridges. But many of these concrete structures are deteriorating years before they should says a recent National Research Council report. The bill for replacing and repairing existing concrete structures is estimated at several hundred billion dollars. Future maintenance costs for similar structures could be radically trimmed if currently available technologies were used on the construction site, the Research Council committee contends. Furthermore, if new ways to make concrete more durable were applied, even greater savings could be realized, the report says.

Changes are on the horizon, however. "Within the next decade concrete will be more predictable as well as stronger and more durable," says Dr. Geoffrey Frohnsdorff, chief of the Building Materials Division at the National Bureau of Standards.

Using computer technology com bined with sophisticated techniques such as electron microscopy and computer image analysis, researchers in the NBS Center for Building Technology are among a small group of scientists worldwide who are ushering in these changes by learning more about the science of concrete. This research will form the basis for new techniques and tools which can help predict the performance, strength, and durability of concrete based on its composition.

\section{Getting Down to Basics}

At the heart of the NBS research are studies on the chemistry and physics of concrete. Concrete does not harden by drying, as is often thought. It hardens because of a complex set of reactions in which the water and cement combine

This research will form the basis for new techniques and tools which can help predict the performance, strength, and durability of concrete based on its composition.

chemically to form new compounds. Initial setting may take a few minutes or several hours. But this whole hydration process continues for months and even years as the material contınues to gain strength

Dr. Paul Brown, a materials scientist at NBS, is developing a computer model to simulate hydration of portland cement. Understanding this process is important. says Brown, because it is hydration that controls how the internal structure of concrete called the microstructure-is formed

As with other materials, it is the microstructure that ultimately determines the characteristics of concrete, such as strength and durability. Just how these charac teristics are linked to the microstructure is still uncertain, however NBS materials scientist Dr. Hamlin 
Jennings is developing a computer model which will correlate information on hydration and microstructure with physical properties and ultimately with performance.

'Once you've got the rules right the model can be used in a number of ways," says Jennings, "such as predicting how a particular mix of concrete will behave in the environment and the structure. It could also be used as a teaching tool." He believes the model will serve as a prototype to simulate the development of microstructure in other materials such as ceramics.

Basic research helps the NBS scientists understand why structures fail. A reaction that sometimes occurs between different compounds in hydrating cement and in the aggregate causes the concrete to slowly expand and crack, and ultimately may cause the structure to fail. "It is an expensive problem that is particularly troublesome for structures, such as dams or bridges, that you expect to last for a long time," says Dr. Leslie Struble, an NBS materials research engineer. Struble is studying the reaction to better understand the mechanisms by which it occurs. "If we know how and why the reaction occurs we stand a better chance of developing ways to prevent or control it," she says.

The NBS research team also is studying the scientific aspects of a recent development in concrete technology. Typical ready-mix concrete can support loads of 3,000 to 5,000 pounds per square inch (psi) But, scientists believe concretes with strengths of 30,000 psi or more can be achieved by mixing chemical or mineral admixtures in with the other ingredients.

But like other new products, a lack of standards and experience with these admixtures presents certain problems, says Frohnsdorff
According to the National Research Council report, the development of tests for determining long-term durability has not kept pace with the development of new materials. One of the biggest problems is the need for quality control standards for evaluating mix design and per-

\section{"If we know how and why the reaction occurs we stand a better chance of developing ways to pre- vent or control it."}

formance of high-strength concrete In many cases, guidance from industry groups is not yet available and equipment in some testing laboratories is not sufficient for measuring the strength of these new materials.

Says Frohnsdorf, "Using admixtures to achieve stronger concretes is a great advance in concrete technology. But we lack a fundamental understanding of how they work." The NBS research team will be studying the factors which control strength development. Their research will form the basis for test methods and standards for evaluating the performance of high-strength concretes, adds Frohnsdorff.

\section{Better Tools}

In addition to these longer-term, fundamental studies, NBS researchers are developing tools to help industry better control the performance of concrete.

In conjunction with the American Concrete Institute $(\mathrm{ACl})$, Dr. James Clifton, NBS research chemist, is designing an easy-to-use "expert system" to help builders get advice on selecting constituents for durable concrete. The system is a computer program that uses facts along with the judgment of experts from $\mathrm{ACl}$. The NBS system-called DURCON, for DURable CONcrete-asks a series of questions, such as "Will the concrete be used indoors or out?" "Will it be exposed to moisture?" "Will reinforcing steel be used?" Based on the answers, the program will recommend an appro priate mixture of materials

Drs. Nicholas Carino and Mary Sansalone, NBS civil engineers, are using an old technique in a new way to find flaws in concrete. Known as "impact-echo," the technique works on the same principle as the sonar pings used to locate and determine the depth of a submarine. An impact on the concrete generates sound waves which are reflected by flaws inside the concrete. A receiver mounted on the surface of the concrete picks up the reflections, or echoes. The location of a flaw is determined by measuring how long it takes to receive the reflected echo. "The technique can be used in either plain or reinforced concrete to determine where flaws are and to estimate their sizes," says Carino.

Although more work needs to be done, Carino and Sansalone feel the research will soon form the basis for a simple, easy-to-use method that will be used routinely to evaluate concrete. 


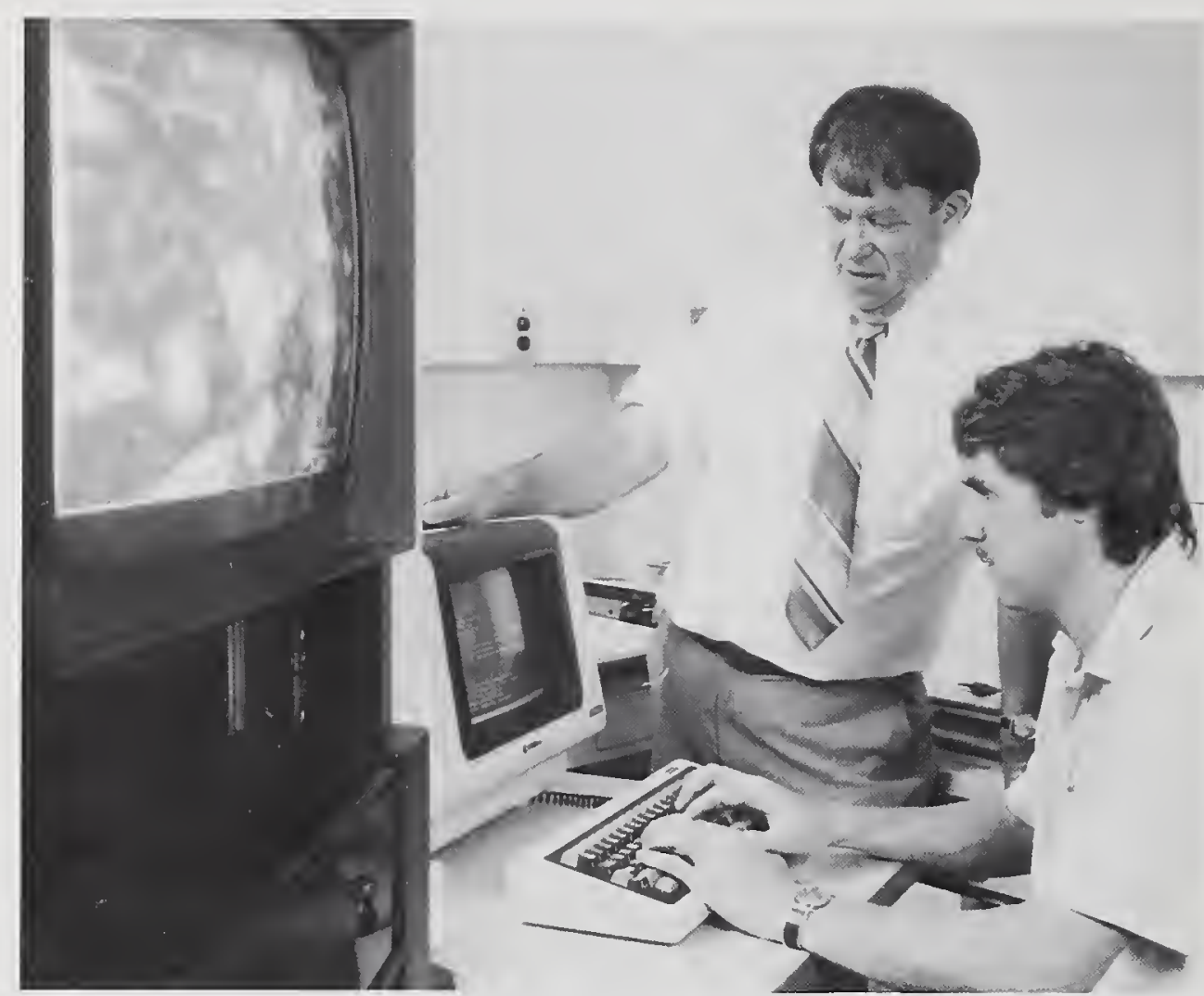

Drs. James Clifton (standing) and Hamlin Jennings discuss a computer model which will help correlate information on hydration and microstructure with the physical properties of concrete and, ultimately, its performance.

\section{Determining Strength}

Another area being studied by NBS will give builders more confidence in determining when newly placed concrete is strong enough for the construction formwork to be removed. Says Dr. H.S. Lew, NBS research structural engineer, "A builder wants to remove the formwork as soon as possible so he can get on with the building. But he doesn't want to risk the safety of the construction workers." Lew and several coworkers have developed a method based on statistics for analyzing field tests used to measure the in-place strength of concrete. This new method is more accurate and reliable than those currently being used in the industry, says Lew. The procedure has been programmed and can be used on a personal computer, he adds. The American Concrete Institute is incorporating the method into its standard practices.

Strength is also a major consideration when designing concrete structures to resist earthquakes. NBS researchers recently completed the first full-scale laboratory test in the United States of a concrete bridge column subjected to earthquake-like stresses. A second column is being fabricated at NBS and testing is scheduled to begin soon. "This work will give us firsthand knowledge of how very large concrete structures perform during earthquakes," says Dr. Charles Culver. chief of the NBS Structures Division

A companion series of tests on six smaller versions of the col-

\section{"This work will give us firsthand knowledge of how very large concrete structures perform during earthquakes."}

umns has been conducted to determine if research on small specimens can be extrapolated to the large sizes. The National Science Foundation, Federal Highway Administration, and California Department of Transportation are lending support to this project.

The challenges and difficulties in making concrete more predictable and improving its strength and durability are great, agree most experts. But, says Frohnsdorff, the future has never looked brighter. He says, "Thanks to computer technology and advanced research, we are filling gaps in our knowledge of cement and concrete and are making strides toward stronger, longer-lasting materials."

by Jan Kosko

NBS Public Affairs Specialist 


\section{Improved Clinical Lab Tests: Goal of Cooperative Program}

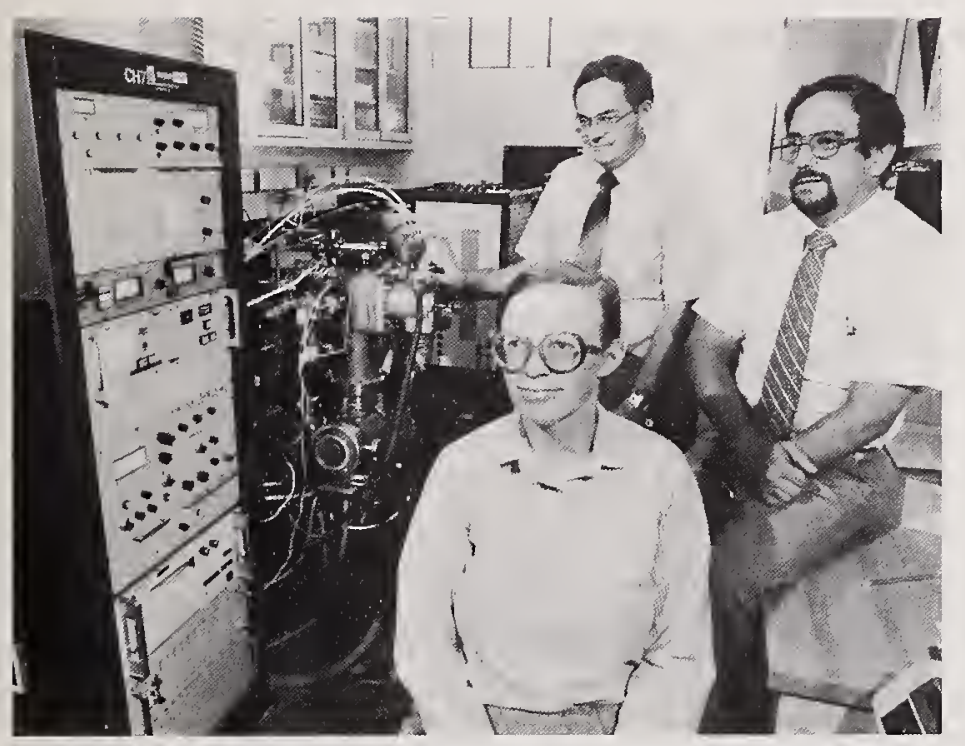

(From left) Drs. Polly Ellerbe, Michael Welch, and Harry Hertz pose beside laboratory equipment used for making extremely accurate measurements of blood cholesterol levels. techniques to certify the accuracy of serum samples sent to laboratories as part of the CAP Surveys Program. This program, in which clinical laboratories nationwide are periodically asked to analyze serum samples and report their values to CAP, is a barometer of how well labs are performing clinical tests.

The new reference laboratory program expands the earlier joint agreement and places special emphasis on development of affordable clinical reference samples that laboratories can buy and use to check or improve their measurement reliability

One area of great concern as the new program gets under way is the accuracy of cholesterol tests in clinical laboratories. Though the links between high blood cholesterol amounts and heart attack risk have been demonstrated, there is currently no guarantee that a single blood test will yield an accurate picture of an individual's cholesterol level. A 1985 CAP survey, in which identical serum samples were sent to several thousand clinical laboratories for cholesterol analysis, concluded that about half produced results that were insufficiently accurate to meet new cholesterol measurement goals.

For patients, imprecise measure ments can have serious consequences. If cholesterol amounts are measured falsely to be high, a person could be placed on medicatión, with its potential side effects, when diet and exercise may be all that are necessary. Conversely, a false low reading might cause a patient's cholesterol level to be overlooked when it needs attention.

Though improving the track record of some laboratories will not be an easy task, the CAP/NBS reference laboratory program is a big step in the right direction, says CAP President Robert L.

Breckenridge. "We established the program with NBS to combine the reputation and capabilities of NBS in measurement science with CAP's influence in the clinical community," he says. "Our aim is to produce reliable methods and materials for clinical laboratories, but that alone is not the answer. Labs must voluntarily use these aids before they can do any good, so we are getting the word out about the benefits."

The first product from the new collaboratıon will be a kit of freezedried human serum reference materials certified for high, average and low cholesterol concentrations. It will sell for $\$ 42.50$ and include sIx vials of serum (two samples of each concentration).

Because these materials are certified to be accurate, clinical laboratories can use them as "yardsticks' to measure the reliability of their cholesterol measurements and methods. The freeze-dried serum can be reconstituted into a liquid and run through the same procedures as a patient's sample.

Scientists in the reference labora tory program also plan to develop a series of reference materials that would check the accuracy of urine drug testing methods and equipment. One proposed material is freeze-dried urine certified for the concentration of benzoylecgonine the principal urinary metabolyte of cocaine. The material will be prepared by CAP and certified by NBS, and additional drugs-in-urine reference samples should follow.

NBS and CAP also emphasize that although these reference materials could be used to check the accuracy of commonly used screening tests for drug abuse. they are mainly intended for the more sophisticated analyses often relied upon to confirm screening tests that produce positive results. J.H. 


\section{Emerging Technologies: The Competitive Edge of the Future?}

The following text is adapted from remarks made by Deputy Secretary Clarence J. Brown at a press briefing June 9, 1987.

$\mathrm{t}$ is no secret that this country has a trade problem. Likewise, it is no secret that at least part of the problem has been our inability to take full commercial advantage of scientific and technological develop ments made in the United States. Time and time again we have seen foreign competitors, most notably, but not exclusively, the Japanese turn our technological developments into their commercial product successes.

I think it is fair to say that the country has awakened to this dilemma. The national attention to the general subject of competitiveness is evidence of our awakening. The President has put forward a comprehensive package of proposals to deal with this problem, and the Administration is taking a series of steps to improve our situation.

I want to take a longer view of our trade and technology position. I want to draw attention to the future and to the technologies that just now are emerging from the laboratory and seem particularly promising in both a scientific and commercial context. I am firmly convinced that America's ability to exploit a new set of emerging technologies with huge market potential in the year 2000 and beyond will play a big role in determining the country's economic successes or failures well into the next century.
Recognizing the importance of these technologies, I asked a group of technical experts and top officials from Commerce Department agencies to examine the latest scientific and technological advancements and to report to me on which technologies seemed especially important, what barriers stood in the way of their commercialization within the United States, and what steps could be taken to remove those obstacles.

\section{...America's ability to ex- ploit a new set of emerg- ing technologies with huge market potential in the year 2000 and beyond will play a big role in de- termining the country's economic successes or failures well into the next century.}

This group, headed by NBS Director Dr. Ernest Ambler, studied scientific and industrial plans and the commercialization process here and abroad. They identified 17 emerging technologies in 7 major groups which are expected to lead to new products or processes in the future. Among other things, the review panel considered the expected contribution of each technology to the gross national product.

The major technologies identified by the group are: advanced materials, electronics, automation, biotechnology, computing, medical technology, and thin-layer technologies. (See detailed table on pages 26 and 27.)

This list is not meant to be cast in concrete. For example, since the original list was put together, there have been significant and highly publicized breakthroughs in the development of superconductors-materials that have absolutely no electrical resistance. (See article on page 5.) Basic scientific questions and great technical problems need to be solved before we can realize the economic potential of these high-temperature superconductors, so for now they must remain a potential emerging technology.

But all you have to do is to look at one possible application for these superconductors, the transmission of electrical energy, to realize the enormity of their promise. We now spend $\$ 160$ billion a year on electrical power in this country, and we waste a full 20 percent of that power due to losses in transmissions. If high-temperature superconductors can be developed to the point where they can be substituted for conventional electrical transmission wires, we could save more than $\$ 30$ billion a year.

When I talk about the potential of emerging technologies, that is what I am talking about, a revolution that could affect every industry in America and around the globe. But there are some familiar barriers to achieving maximum economic benefits from emerging technologies.

The relatively high costs of capital funds and the less favorable tax 
incentives in the United States compared to foreign competitors top the list. Management's focus on short-term, rather than longer

\section{But there are some famil- iar barriers to achieving maximum economic bene- fits from emerging technologies.}

range, goals for returns on investments combined with poor integration of manufacturing, design, and research and development functions within U.S. firms and the lack of cooperation among American institutions hurt our chances of exploiting emerging technologies.

So do inadequate laws, regulations, and enforcement protecting intellectual property rights in the United States or overseas. Complacency and a dependence on the domestic market-the lack of awareness of the need to compete with Japan and other countries head-to-head in the international marketplace-are a basic stumbling block.

Restrictive trade policies in foreign markets; federal or state regulations on corporate activities; export controls on advanced technologies and high-technology products; restraints and uncertainty caused by product liability and tort laws; and anti-trust restrictions-real and perceived-against cooperative ventures for $R \& D$, marketing, or production are all formidable barriers to the commercialization of these emerging technologies.

Now, what do we do about breaking down these barriers? Our recommendations include:

$\square$ Continued vigilance to reduce federal budget deficits and to avoid high interest rates which affect the cost of capital.

$\square$ Creation of venture capital pools at the state and local levels.

$\square$ Additional tax incentives and other actions to increase aggregate savings.

$\square$ A commitment to making future changes in the tax laws focus on the incentives available for modernization investment in all stages of production, marketing, and distribution.

$\square$ Fostering participative management by employees.

$\square$ Training managers in the production process and updating business school curricula.

$\square$ Eliminating provisions in foreign tax laws and regulations that discriminate against U.S. products

$\square$ Improving export controls, reforming product liability and tort laws, and lifting antitrust restrictions.

In a recent hearing before the Committee on Commerce, Science and Transportation, Senator Fritz Hollings complained, "America may still invest enough in research to win most of the Nobel Prizes, but the Japanese make all the profits on them." Well, we cannot let that continue to happen. As you can see by looking at the barriers and recommendations for commercializing emerging technologies, the government has an important role to play. But the private sector-the people who work in and run America's factories and board rooms - must take the lead.

This country has done enough looking back and talking about how many different areas of technology we have already lost to the commercial competition. Our look ahead at critical emerging technologies should be a warning that unless we pull together and take swift action now to break down the barriers to the commercialization of new technologies, we are going to be facing the same international trade problems we confront today right on into the next century.

We have made some progress. Although we neither talk nor read

\section{..the private sector-the people who work in and run America's factories and board rooms-must take the lead.}

enough about them, this country has some wonderful success stories and some good things happening to show that businesses and even entire industrial sectors can and are taking decisive actions to improve the situation. We have firms joining together in research consortia, corporations cutting down on excessive managerial positions, companies finding new market niches overseas. We simply must be vigilant and make additional changes now if the country's economic future is to be bright when the new century arrives. 


\section{Emerging Technologies}

\section{Technology \\ ADVANCED MATERIALS}

Ceramics (high-

performance structural and electronic ceramics)

Polymer Composites (highstrength, fiber-reinforced plastic resin)

Metals (rapid solidification, metal matrix composites)
What does it do new or better?
Applied to what products or processes?
Used by what

major industries?
Better high-temperature strength-to-weight properties

Better dielectric and optical properties

Higher strength-to-weight ratio

Design flexibility because of spatial asymmetry

Improved strength and high-temperature performance

Improved magnetic properties

\section{ELECTRONICS}

Advanced Microelectronics (enhanced VLSI and VHSIC chips)

Optoelectronics (optical fiber and light wave processing)

Millimeter Wave Technology

\section{AUTOMATION}

Manufacturing (computerintegrated and flexible systems)

Business and Office Systems (computer applications within an organization)
Improved performance in speed and size

Improved magnetic properties

Higher efficiency photovoltaic conversion

Improved performance in speed, size, capacity, and security

Higher density information storage

When replacing radio systems it frees RF

Flexible reconfiguration of production processes

Integrated control of all production operations

Efficient information storage, retrieval, and exchange spectrum for other uses
Heat engine components, turbine blades, heat shields

Electronic substrates, integrated optics

Structural components

Structural components

Structural components, superconducting components

Electromagnetic equipment

Semiconductor devices

Information storage

Solar cells

Electronic equipment, information processing

Computer systems of all sizes

Voice and data communication systems

All manufacturing processes

Networking, word processing, database management
Automotive and aircraft engines

Electronic components

Aerospace, automotive, industrial construction

Aerospace, automotive, industrial construction

Manufactured components

Electrical machinery

Electronic and optical components and systems

Information processing

Energy generation

Communications computers

Computers

Telecommunications carriers, corporate use for private circuits

All manufacturing

All organizations 


\begin{tabular}{llll}
\hline Technology & $\begin{array}{l}\text { What does it do } \\
\text { new or better? }\end{array}$ & $\begin{array}{l}\text { Applied to what } \\
\text { products or processes? }\end{array}$ & $\begin{array}{l}\text { Used by what } \\
\text { major industries? }\end{array}$ \\
\hline
\end{tabular}

Technical Services

(computer applications in

the provision of

commercial services)

\section{BIOTECHNOLOGY}

\section{Genetic Engineering} (design and production of highly selective agents)

\section{Biochemical Processing}

\section{COMPUTING}

Computing Equipment (supercomputers, parallel processing, computer architecture)

Artificial Intelligence Techniques (inc/udes expert systems, natural language, robotic control)

\section{MEDICAL TECHNOLOGY}

Drugs (other drugs are included under

Biotechnology)

Instruments and Devices

\section{THIN-LAYER}

\section{TECHNOLOGY *}

Surfaces and Interfaces
Efficient high-volume information storage, retrieval, and exchange

Improved diagnostic and therapeutic drugs

Improved plants, pesticides, and animal supplements

Neutralize pollutants

Improved control of chemical processes, outputs, and yields

\section{Faster, lower-cost} computing

Improved computer replication of human judgment

Improved immunology and treatment

Improved diagnostic and therapeutic systems

Improved control and yield of chemical reactions

New electronic and optical properties

New chemical properties, better chemical separation techniques
Information retrieval and distribution, database management, education and training

Financial services, electronic mail, telecommunications, professional service

Health services

Foods, pesticides

Environmental control processes

Chemical separations and reactions, biosensors

Information processing, computer control

Information processing, computer control

Health services

Medicine, pharmaceuticals

Magnetic resonance imaging, CAT scanning, radiation treatment

Chemical catalysis

Semiconductor devices, surface modification and coatings

Chemical separations
Medicine, pharmaceuticals

Agriculture, food processing

Chemical manufacturing and treatment

Chemical manufacturing
All applications using computers
Medicine

Chemical manufacturing, food processing

Electronic components, computers

Chemical manufacturing, food processing 


\section{High-Technology Bugs Are New Tools for Science and Industry}

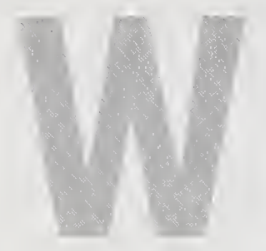

hen Drs. Frederick E. Brinckman and Gregory J. Olson tell people that they work with high-technology bugs, most people próoably figure their research involves electronic listening devices. It doesn't.

Research chemist Brinckman and microbiologist Olson, with the National Bureau of Standards, are working with more traditional types of bugs-living microorganismsthat can be put to use producing new, advanced materials for electronics, aerospace, and other hightechnology products.

Medical researchers have been studying disease-producing viruses and bacteria for more than a century, and for the last 20 or 30 years scientists have been able to identify some of the microorganisms that feed on minerals locked in ore deposits. But it is only recently that scientists have paid much attention to the potential for putting these bugs to work in processing materials.

"These tiny microbes are found all over the Earth, from the tops of mountains to the bottom of seas, and they even thrive at pressures and temperatures that are hostile to all other forms of life," says Olson

"With advances in science. we now know that microorganisms have been processing materials for about 3.5 billion years.

Examples of this natural biogenesis include minerals containing such elements as iron, manganese, magnesium, silicon, and calcium produced by a variety of microorganisms that include bacteria, algae, and protozoa. For instance. some of the Earth's deposits of calcium compounds are made by the accumulation of shells from simple invertebrate organisms.

Brinckman, head of the project says, "There are tremendous opportunities for harnessing microorganisms in various bio- processing techniques. They also can play an important role in the recovery of our planetary

spaceship's limited supply of scarce elements from wastes."

Because microorganisms can be used to produce very pure

materials of specific composition as well as to recover others, scientists at NBS are working to develop the basic measurement tools industry and government will need for several new bioprocessing technologies.

The job is difficult, the scientists explain, because microorganisms behave in a variety of ways: Different strains do different things. There are organisms with appetites for certain minerals. Others are able to detoxify heavy metals such as mercury, and some can oxidize insoluble materials to unlock elements that are bound into them. Still other organisms secrete compounds to trigger various chemical and biological processes, some of which lead to corrosion.

Perhaps one of the most potentrally useful groups of microorganisms for industry are those that feed on metal ores to obtain their energy for survival. They can be used in bioleaching methods that have been shown to be more economical and less polluting than conventional techniques used to extract minerals such as smelting

While these organisms do not ingest metals, they release material bound into ores so that it can be flushed out and collected. These microorganisms currently are being used to remove copper and uranium from low-grade ores on a large scale.

Pilot plant studies show a dramatic increase in the yield of gold from pyrite when organisms are used in a preleaching step to dis solve the tough pyrite matrix that shields the metal from extracting chemicals

There are even microorganisms that thrive on metallic ions and toxic substances in water. They can accumulate up to 50 percent of their weight with other materials and be used in various bioaccu mulation methods to purify water by absorbing dissolved metals and breakıng down solid wastes.

The NBS scientists explain that progress in harnessing microorganisms is inhibited by incomplete knowledge of various metabolic processes. For example, many organisms can be found in ore deposits. The questions are which ones are best for carrying out different processes, what factors limit their reaction rates, and how can industry manipulate the various environmental conditions such as light, oxygen, moisture, or temperature that are required for organisms to do their work?

"These are a few of the great unknowns at this point,"

\section{"There are tremendous opportunities for harness- ing microorganisms in various bioprocessing techniques."}

Brinckman says "And this is where NBS can help industry by developing standards and procedures for the bioprocessing of materials."

\section{Cooperative Efforts}

Bureau scientists are looking at a number of measurement tools and techniques. These might include certified samples of ores for conducting standardized tests to identify preferred strains of organisms and bioprocessing conditions. 


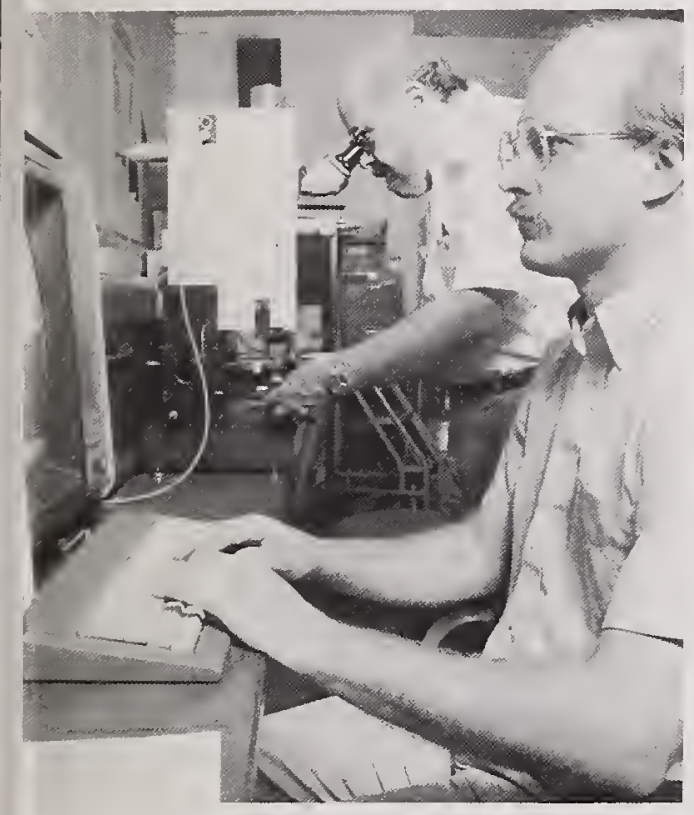

Drs. Gregory Oison (front) and Frederick Brinckman work with a microscopic Fourier-transform infrared spectrometer to characterize nondestructively the surface of materials undergoing bioprocess.

The scientists have established several collaborative links with industry and other organizations to carry out their work. Olson chairs a new task group on microbial ore leaching under ASTM Committee E-48 on Biotechnology. This voluntary standards-writing group is working to develop standard procedures for conducting bioleaching studies.

In cooperation with the American Iron and Steel Institute, NBS scientists are investigating the types of organisms that can be used by industry in two bioprocesses: the removal of copper from steel scrap so that the steel can be used for recycling and the removal of insoluble phosphorous from domestic iron ore to make it more desirable for specialty steel products. Future work may include the development of reference materials for the quality control of these new bioprocesses.
In another cooperative effort proposed with the Electric Power Research Institute, Bureau researchers plan to explore the use of microorganisms in coal-cleaning processes to reduce the fuel's sulfur content Various types of organisms might be grown in high temperature bioprocessing reactors at Johns Hopkins University and at NBS to determine which ones can be used to remove sulfur. This research also may examine the use of organisms as measurement tools to identify certain forms of sulfur in coal.

In joint efforts at NBS and Johns Hopkins University, scientists are studying the metabolism of bacteria attached to ore surfaces. By coloring the organisms with stains and using a microscopic flucrescence imaging technique, the researchers are able to monitor the activities of bacteria by cell color. This information will be used to develop measurement standards for controlling organisms in bioprocesses.

Bureau scientists also are helping the Office of Naval Research to evaluate the potential use of microorganisms to recover strategic materials such as cobalt, chromium, and nickel from smelter wastes. Microorganisms also could be used to extract these materials from domestic low-grade ores.

In another project for the Navy, NBS researchers are evaluating the performance of coatings for ship hulls that contain tributyltin to prevent the growth of algae and barnacles. Even though this project is aimed at preventing fouling which is costly to remove, the control of microbiofilms on surfaces may lead to new protective coatings.

In another effort, the NBS scientists are consulting with the Air Force to evaluate techniques in which microorganisms are used to recover gallium from domestic low- grade ore deposits to improve the supply of this largely imported material for high-technology electronics.

NBS scientists also participate in technical symposia and consult with a wide group of industry associations, universities, and government agencies which have a growing Interest in microorganisms to process materials. These organizations include the National Center for Resource Recovery, Idaho Mining Association, Cleveland Cliffs Iron Co., St. Joe Lead Co., American Cyanamid, Mobil Oil Corporation, University of Cincinnati, Johns Hopkins University, Bureau of Mines, U.S. Department of Energy U.S. Environmental Protection Agency, and the Defense Advanced Research Projects Agency.

NBS has a number of specialized facilities at its disposal to help develop the new measurement and research tools needed to exploit microorganisms for materials processing. These instruments include graphite atomic absorption furnaces for identifying elements in materials, epifluorescence electron microscopes for studying the structures of materials as well as the behavior of organisms, and a small-angle neutron scattering (SANS) facility at the Bureau's research reactor which uses low-energy neutrons as probes to measure the internal structures of materials. These and several other laboratories for conducting research on materials bioprocessing also are available to those in industry and other organizations for collaborative or independent research. For additional information, call Dr.

Frederick Brinckman, A329 Materials Building, NBS, Gaithersburg, MD 20899, 301/975-5737.

by Roger Rensberger NBS Public Affairs Specialist 


\section{HISTORY OF NBS RADIO RESEARCH}

Snyder, W.F. and Bragaw, C.L., Achievement in Radio: Seventy Years of Radio Science, Technology, Standards, and Measurement at the National Bureau of Standards, Natl. Bur. Stand (U.S.), NBS Spec. Pub. 555, 842 pages (October 1986). Order by stock no. 003-003-02762-6 from GPO, \$55 prepaid.

A massive project to compile the definitive history of radio research at NBS has culminated in this publication. Achievement in Radio is a comprehensive, exhaustive treatment of the accomplishments and people of the Bureau, always set in the context of external events and developments. NBS was only 10 years old, and practical radıo only about 25 , when NBS made its first official radio measurement in 1911, a calibration of a wavemeter. This book tells the story of NBS' involvement in radio science, from those spark-and-crystal origins to today's integrated circuits, masers, and satellites. The authors write from firsthand knowledge of most of the period covered.

\section{NBS STUDY OF 1985 MEXICO CITY EARTHQUAKE}

Stone, W. C., Yokel, F.Y., Celebi, M., Hanks, $T$., and Leyendecker, E.V., Engineering Aspects of the September 19, 1985 Mexico Earthquake, Natl. Bur. Stand. (U.S.), NBS BSS 165, 215 pages (May 1987). Order by stock no. 003-003-02803-7 from GPO, $\$ 10$ prepaid.

Shortly after the September 19, 1985 , earthquake in Mexico City, a research team from the NBS Center for Building Technology and the U.S. Geological Survey traveled to the site to provide technical advice to the rescue effort and to assess structural damage. This NBS report highlights the findings of the team. The primary cause of the severe structural failure was unusually strong ground accelerations combined with an exceptionally long duration of shaking. While some areas of Mexico City suffered devastating structural failures, other areas were only slightly affected. Variations in subsurface conditions account for the selective pattern of damage. The researchers compared the response of the structures with Mexican and U.S. design provi- sions and found that even buildings specified for the most severe conditions could have failed in this earthquake. The implication of this finding is that special provisions should be considered for structures built over areas that have deep clay deposits similar to those found in Mexico City.

\section{INTRODUCTION TO STANDARDS ACTIVITIES PUBLISHED}

\section{Breitenberg, M.A., The ABC's of} Standards-Related Activities in the United States, Natl. Bur. Stand. (U.S.), NBSIR 87-3576, 23 pages (May 1987). Order by sending a self-addressed mailing label to: Maureen Breltenberg, A629 Administration Building, NBS,

Gaithersburg, MD 20899, telephone 301/975-4031.

This introduction to voluntary standardization, product certification, and laboratory accreditation programs in the United States is designed to provide information for users who may not be familiar with various areas of standardization and the relationships between groups. Information is provided on the history of standardization, types of standards, private standards groups in the United States, standards development procedures, and the benefits and problems of standardization such as participation in the standards process by qualified consumer representatives.

\section{THE FUTURE OF AUTOMATED MATERIALS PROCESSING}

Bloom, H.M. and Kuchar, N.R., editors, A National Forum on The Future of Automated Materials Processing in U.S. Industry-The Role of Process Models, Artificial Intelligence and Computer Integration, Natl. Bur. Stand. (U.S.), NBSIR 87-3544, 48 pages (April 1987). Order by stock no. PB 87-200382 from NTIS, \$11.95 prepaid.

The rapid pace of new technology has brought a wide variety of new materials into engıneered systems. Often their processing is far from mature and the materials are only one step from the research laboratory. This is one of the many problems facing process industries that is discussed in this publication. The report is from the second of two workshops sponsored by the Industrial Research Institute and the White House Office of Science and Technology Policy, Committee on Materials, in cooperation with the General Electric Company and NBS. At the May 1986 workshop, experts from industry, academia, and government addressed several technologies that can play an important role in improving the competitiveness of U.S. process industries through automation. In working sessions, participants identified state-of-the-art and technical needs in such areas as process modeling, artificial intelligence, and computer integration as applied to materials processing.

\section{GUIDE FOR MAKING ECONOMIC ENERGY DECISIONS}

Ruegg, R.T. and Petersen, S.R., Comprehensive Guide for Least-Cost Energy Decisions, Natl. Bur. Stand. (U.S.), NBS Spec. Pub. 709, 229 pages (January 1987). Order by stock no. 003-003-02790-1 from GPO, $\$ 11$ prepaid.

More than a decade after the first shock from escalating energy prices, millions of buildings in the United States still reflect the days when oil cost just pennies per gallon. Many buildings continue to be designed and constructed with little consideration for energy conservation. The resulting cost to building owners and the nation is enormous. A new guide by researchers in the NBS Center for Applied Mathematics will help builders and building designers, owners, and operators find a balance between energy consumption and energy conservation which will result in more costeffective building. The publication guides the decision maker to ask the right economic questions. It also shows how to structure problems for solution, how to estimate future cash flows, and how to interpret various measures of economic performance. Worksheets, a computer program, and data tables to assist with evaluations are provided in the publication. In addition, a computer program diskette is available from several vendors for under $\$ 20$ and will shortly be available from NTIS. Diskette ordering information is in the publication. 


\section{REVISED KWIC INDEX OF ENGINEER- ING STANDARDS}

National Center for Standards and Certification Information Staff, Key-Word-InContext (KWIC) Index of U.S. Voluntary Engineering Standards, Natl. Bur. Stand. (U.S.), 11 microfiche sheets (March 1987). Order by stock no. PB 87-133377 from NTIS, $\$ 18$ prepaid.

NBS has updated its KWIC index for use by manufacturers, exporters, importers, and others concerned with standards developed by U.S. trade associations and technical and professional societies. The index contains more than 28,000 titles of standards developed by approximately 400 U.S. standards organizations. First published in 1971, the revised microfiche index provides the title, date, source, and number of the standard for each entry. Each standard can be found under all significant keywords in the title. The date of publication or last revision, the standard number and an acronym designating the standardsissuing organization appear as a part of each entry.

\section{SEISMIC DESIGN GUIDELINES}

Prepared by the Interagency Committee on Seismic Safety in Construction, Seismic

\section{Design Guidelines for Federal}

Buildings, Natl. Bur. Stand. (U.S.), NBSIR 87-3524, 102 pages (February 1987). Order by stock no. PB 87 . 161204/AS from NTIS, $\$ 18.95$ prepaid.

NBS, as secretariat of the Interagency Committee on Seismic Safety in Construction, has issued guidelines for federal agencies to use in designing and constructing buildings to resist earthquake damage. The report was prepared as part of the National Earthquake Hazards Reduction Program. The guidelines are based on existing voluntary standards, model building codes, and federal regulations. In particular, the technical content is similar to the seismic design requirements on the 1985 Uniform Building Code published by the International Conference of Building Officials. The report includes information on site planning, structural design criteria, structural analysis procedures and design details, as well as design and construction standards for structural materials including steel, concrete, and wood. In addition, it includes nonstructural design requirements, such as protecting against secondary hazards and information on quality control and inspection

\section{GATT STANDARDS CODE ACTIVITIES FOR 1986}

Overman, J.R., GATT Standards Code Activities of the National Bureau of Standards 1986, Natl. Bur. Stand. (U.S.), NBSIR 87-3538, 32 pages (March 1987). Order through JoAnne R. Overman, Standards Code and Information, A629 Administration Building, NBS, Gaithersburg MD 20899, telephone 301/975-4037.

Manufacturers, exporters, and others engaged in international trade will be interested in this annual report which describes NBS work over the past year as the official U.S. GATT (General Agreement on Tariffs and Trade) inquiry point for information on standards and certification activities. This includes assisting U.S. industry with trade-related problems, coordinating comments on proposed foreign regulations and translations of foreign texts, and operatıng the GATT "hotline" that provides the latest information on foreign notifications from the GATT Secretariat in Geneva, Switzerland. Highlights of 1986 include publication of a directory of federal certification programs, background research for bilateral standards discussion with other GATT signatories, an update of the KeyWord-In-Context (KWIC) Index of U.S Voluntary Engineering Standards, and contributions to the second triennial report to the U.S. Congress on the Standards Code.

1986 LISTING OF NBS PUBLICATIONS Pardee, R.J., editor, Publications of the National Bureau of Standards-1986 Catalog, Natl. Bur. Stand. (U.S.), NBS Spec. Pub. 305, Supplement 18, 389 pages (June 1987). Order by stock no. 003-003-02798-7 from GPO, $\$ 18$ prepaid.

Scientists and librarians in industry, academia, and government will be interested in this new catalog which lists approximately 1,600 reports and journal articles published by NBS and those appearing elsewhere during 1986. Papers published prior to 1986 but not reported previously also are included. Full bibliographic citations including keywords and abstracts for papers published and entered into the National Technical Information Service (NTIS) collection are listed in "NBS Publica tions Announcements." Entries are arranged by NTIS subject classifications and listed alphanumerically by order number. Four indexes are included identify ing papers by author, keywords, title, and NTIS order/report number. The catalog also contains ordering information, availability, and a list of depository libraries.

\section{COMPLETION OF THE FIRST PHASE OF U.S. EARTHQUAKE FACILITY STUDY}

Scribner, C.F and Culver, C.G. National

Earthquake Engineering Experimental Facility Study: Phase One-Large Scale Testing Needs, Natl. Bur. Stand. (U.S.). NBS Spec. Pub. 729, 70 pages (April 1987). Order by stock no. 003-00302795-2, \$3.50 prepaid.

In 1985, researchers in the NBS Center for Building Technology began a 4-year conceptual engineering design study for a national earthquake engineering experımen tal facility. The study was recommended by the National Research Council to the White House Office of Science and Technology Policy. During this past year the NBS researchers worked with a broad spectrum of professional engineers, researchers, industry representatives, building officials, and federal agency representatives to find out therr needs for large-scale seismic testing. Twenty-three high-priority tests of large scale structures and components were identified in five areas including lowmedium-, and high-rise buildings and industrial processing and power facilities.

\section{ORDERING INFORMATION}

To order publications from NTIS, send request with payment to: Natıonal Technical Information Service, Springfield, VA 22161. Publications can be ordered from GPO by mailing order with payment to: Superintendent of Documents, U.S. Government Printing Office, Washıngton DC 20402 


\section{Information Resources Management: Standards for Future Information Services, NBS, Gaithersburg, MD \\ December 3, 1987}

Increased complexity of computer systems. growing user requirements to transfer data and processes from one system to another and strong international requirements for standards are some of the forces driving the standards development process for information technology. As a result of these forces, standards developers are producing a complex series of architectural models and standards that provide a framework for integrating data, voice, and pictures for a variety of new applications. This conference will highlight new and emerging standards that meet user requirements for advanced integrated systems. Discussions will center on issues related to implementing these standards as part of the information resources management process. Sponsored by NBS and the General Services Administration. Contact: Shirley Radack. B151 Technology Building, NBS Gaithersburg, MD 20899, 301/975-2833.

\section{Microstructure and Macromolecular Research with Cold Neutrons, NBS, Gaithersburg, MD}

December 8-9, 1987

A major expansion of the neutron scattering facilities at the NBS 20-megawatt research reactor is now under way. The Cold Neutron Research Facility (CNRF), scheduled for completion in 1989, will provide cold neutron beams for many new types of experımental facilities, including several with specialized capabilities for the study of structure and dynamics of materials

The CNRF is intended to be a national facility serving a broad-based community of researchers in materials science, physics, chemistry, and biology. In an effort to inform and involve this community at an early stage while conceptual and detailed planning for instrumentation for the facility is progressing. NBS is hosting a series of workshops, each of which will deal with a major area of cold neutron research.

This workshop will focus on the scientific opportunities in the study of submicron structures in materials, including macromolecular structures in polymers and biomaterials, which arise from experimental techniques that take special advantage of cold neutrons. Technical talks by invited speakers will review current work in a variety of disciplines and discuss future extensions utilizing cold neutrons. Specific instruments and techniques related to characterizing submicron structures in materials will also be discussed. An important part of the workshop will be the active participation of the attendees in assessing the capabilities of, and the need for, various types of instrumentation for the CNRF. Sponsored by NBS. Contact: Kathy Stang, A345 Physics Building, NBS, Gaithersburg, MD 20899. 301/975-4513.

\section{4th International Conference on Metrology and Properties of Engineer- ing Surfaces, NBS, Gaithersburg, MD \\ April 13-15, 1988}

Metrology and properties of engineering surfaces have continued to assume great importance to both the practicing engineer and the researcher. In recent years, industry has gained increased awareness of the importance of surface preparation techniques. This international conference is the fourth in a series of meetings, held every 3 years since 1976 , on the subject of metrology and properties of engineering surfaces The main topics to be discussed at this meeting will be: the application of new surface techniques in industry; the development of new tactile instruments; the development of new techniques for the optical measurement of engineeririg surfaces: the compilatıon and analysis of data for specific manufacturıng processes; and the relationships between surface generation and practical performance. Sponsored by NBS, Coventry Polytechnic, and Whitestone Business Communications. Contact: Professor K.J. Stout, Coventry Polytechnic, Department of Manufacturing Systems, Priory Street, Coventry CV1 5FB. England, 0203 24166, ext. 278; or Ted V. Vorburger, A117 Metrology Building. NBS, Gaithersburg, MD 20899.

301/975-3493.

\section{Tenth Symposium on Thermophysical Properties Call for Papers, NBS, Gaithersburg, MD}

June 20-23, 1988

This symposium is concerned with theoretical, experimental, and applied aspects of thermophysical properties for gases, liquids, and solids. Appropriate topics to be included in the symposium are: thermodynamic properties; transport properties; optical and thermal radiative properties; interface properties; and data correlation. Special topics will be: properties of new materials, properties of gaseous and liquid mixtures; new developments in experimental techniques; and interpretation of experimental data in terms of new theoretical developments.

Prospective authors are requested to submit a 200-300 word abstract before December 1, 1987. The content of the abstract will be the basis for acceptance of the paper for presentation at the symposium. If the paper is accepted for presentation, then full papers should be submitted by June 23, 1988. Sponsored by the American Society of Mechanical Engineers NBS, and The University of Maryland. Contact: Ared Cezairliyan, Room 124 Hazards Building, NBS, Gaithersburg, MD 20899 , 301/975-5931 or J.V. Sengers, Institute for Physical Science and Technology, The University of Maryland, College Park, MD 20742, 301/454-4117. 
he National Bureau of Standards was established by an act of Congress on March 3, 1901. The Bureau's overall goal is to strengthen and advance the nation's science and technology and facilitate their effective application for public benefit. To this end, the Bureau conducts research and provides: (1) a basis for the nation's physical measurement system; (2) scientific and technological services for industry and government; (3) a technical basis for equity in trade; and (4) technical services to promote public safety. The Bureau's technical work is performed by the National Measurement Laboratory, the National Engineering Laboratory, the Institute for Computer Sciences and Technology, and the Institute for Materials Science and Engineering.

\section{THE NATIONAL MEASUREMENT LABORATORY}

Provides the national system of physical and chemical measurement; coordinates the system with measurement systems of other nations and furnishes essential services leading to accurate and uniform physical and chemical measurement throughout the nation's scientific community, industry, and commerce; provides advisory and research services to other government agencies; conducts physical and chemical research; develops, produces, and distributes Standard Reference Materials; and provides calibration services. The laboratory consists of the following areas:

- Standard Reference Data

- Measurement Services

- Basic Standards

- Radiation Research

- Chemical Physics

- Analytical Chemistry

\section{THE NATIONAL ENGINEERING LABORATORY}

Provides technology and technical services to the public and private sectors to address national needs and to solve national problems; conducts research in engineering and applied science in support of these efforts; builds and maintains competence in the necessary disciplines required to carry out this research and technical service; develops engineering data and measurement capabilities; provides engineering measurement traceability services; develops test methods and proposes engineering standards and code changes; develops and proposes new engineering practices; and develops and improves mechanisms to transfer results of its research to the ultimate user. The laboratory consists of the following centers:

- Applied Mathematics

- Electronics and Electrical Engineering

- Manufacturing Engineering

- Building Technology

- Fire Research

- Chemical Engineering

\section{THE INSTITUTE FOR COMPUTER SCIENCES AND TECHNOLOGY}

Conducts research and provides scientific and technical services to aid federal agencies in the selection, acquisition, application, and use of computer technology to improve effectiveness and economy in government operations in accordance with Public Law 89-306 (40 U.S.C. 759), relevant Executive Orders, and other directives; carries out this mission by managing the Federal Information Processing Standards Program, developing federal ADP standards guidelines, and managing federal participation in ADP voluntary standardization activities; provides scientific and technological advisory services and assistance to federal agencies; and provides the technical foundation for computer-related policies of the federal government. The institute consists of the following divisions:

- Information Systems Engineering

- Systems and Software Technology

- Computer Security

- System and Network Architecture

- Advance Systems

\section{THE INSTITUTE FOR MATERIALS SCIENCE AND ENGINEERING}

Conducts research and provides measurements, data, standards, reference materials, quantitative understanding, and other technical information fundamental to the processing, structure, properties, and performance of materials; addresses the scientific basis for new advanced materials technologies; plans research around cross-country scientific themes such as nondestructive evaluation and phase diagram development; oversees Bureau-wide technical programs in nuclear reactor radiation research and nondestructive evaluation; and broadly disseminates generic technical information resulting from its programs. The institute consists of the following divisions:

- Nondestructive Evaluation

- Inorganic Materials

- Fracture and Deformation

- Polymers

- Metallurgy

- Reactor Radiation 
U.S. DEPARTMENT OF COMMERCE

National Bureau of Standards

Gaithersburg, MD 20899

OFFICIAL BUSINESS

Penalty for Private Use, $\$ 300$
BULK RATE

POSTAGE \& FEES PAID

NBS

PERMIT No. G195 